\title{
RECUERDOS DE SANCTI PETRI EN EL NACIMIENTO DE LA ARQUEOLOGÍA SUBMARINA
}

\section{MEMORIES OF SANCTI PETRI ON THE BIRD OF SUBMARINE ARCHAEOLOGY}

\author{
Olga VALLESPÍN GÓMEZ
}

Licenciada en Filosofía y Letras, especialidad de Historia y Geografía. Buceador Profesional de $2^{\text {a }}$ Clase, ejercicio libre de la arqueología con licencia fiscal. Colegiado CDL de Madrid № 31.951

Correo electrónico: tescartin@hotmail.com

Resumen: En este merecido homenaje a don Antonio Sáez Espligares, me propongo reflejar el valor de las personas y recuerdos inéditos de los primeros pasos de la arqueología submarina en Cádiz, particularmente en Sancti Petri. Deseo que no quede en el olvido, por su gran interés y el papel fundamental que jugó en el desarrollo de la nueva especialidad arqueológica. La investigación iniciada en los primeros años de la década de los 70 del siglo pasado, con la finalidad de elaborar la Carta Arqueológica Submarina de Cádiz, quedó de improviso paralizada por decisiones de la autoridad competente, cuando empezaba a dar sus frutos a mitad de la década 80. Los logros científicos conseguidos con tanto esfuerzo para vencer las dificultades del medio físico, las carencias técnicas y las económicas, fueron cubiertos bajo un manto de silencio. Ya entrado el siglo XXI permanecen casi totalmente olvidadas. Principalmente en la bibliografía posterior, se callan aquellas prospecciones y excavaciones sistemáticas pioneras, presentando sin rubor los escasos trabajos submarinos realizados después, como los primeros en la región con la finalidad de realizar el llamado Proyecto General de Investigación de la Bahía de Cádiz "Carta Arqueológica Subacuática".

Palabras Clave: Sancti Petri, La Caleta, poblado almadrabero, arqueología submarina, pecio, Carta Arqueológica Submarina de Cádiz, prospección submarina, excavación submarina, AMRA, San Pedro, Atlántida, pozos de agua dulce, Pecio del Cobre, Vía Hercúlea, areneros, bronces fenicios, dragados, Dragado de la Canal del puerto de Cádiz, Proyecto Galeón, Fragata Mercedes.

\begin{abstract}
With this well-deserved tribute to Mr. Antonio Sáez Espligares. I am seeking to show the value of people and to convey unknown memories of the first steps in underwater archaeology in Cádiz, particularly in Sancti Petri. I would not want them to be forgotten because of their great value and the key role they played in the development of new branch of archaeology. Research that began in the early 1970s in to create a Submarine Archaeological Map of Cádiz was brought to a sudden end in the mi-1980s by a decision of the competent authorities at a time when it was producing its first fruits. The scientific accomplishments that had been achieved with great personal effort put in to overcome environmental, economic and technical difficulties were shrouded in complete silence. And at the present time, well into the 21st century, they remain totally forgotten. Those systematic surveys and excavations pioneer are being ignored, notably in subsequent literature, which shamelessly quote the very few underwater projects conducted in the region for the purpose of drawing a so-called General Research Project in Cádiz Bay-Sub-aquatic archaeological Map.
\end{abstract}

Keywords: Sancti Petri, La Caleta, tuna fishing village, submarine archaeology, shipwreck, Submarine Archaeological Map of Cádiz, underwater survey, AMRA, San Pedro, Atlántida, sweet water wells, Copper Shipwreck, Vía Hercúlea, dredging boats, Phoenician bronze, dredging, Dredging of the Port Channel, Galeón Project.

Sumario: 1. Introducción. 2. Arqueología Submarina. 3. Prospecciones y excavaciones arqueológicas submarinas. 4. Sancti Petri. 5. Campañas iniciales. 6. El Pecio del Cobre. 7. Paralización de las primeras investigaciones científicas submarinas de Cádiz. 8. Agradecimientos. 9. Bibliografía. 
Esperemos a que algún día las exploraciones submarinas sistemáticamente llevadas en Sancti Petri añadan nuevos datos que amplíen, confirmen o rectifiquen los que hasta ahora hemos podido recoger... (García y Bellido 1964: "Hercvles Gaditanvs").

\section{Introducción}

No se puede separar el objetivo de la arqueología submarina, marina, marítima o naval, porque en cualquiera de ellas es el estudio del impacto de la actividad marinera en las sociedades costeras, la transcendencia en sus costumbres, religión, economía, política y en todas las facetas culturales que imprimen una vocación universal y un carácter tradicional a los pueblos volcados a la navegación. Con el invento de Gagnan-Cousteau de la escafandra autónoma, se abrió un gran abanico de posibilidades de sumergirse en el agua y bucear libremente, llevando a la espalda el aire comprimido en botellas y un regulador de presión, frente al buzo clásico que dependía del aire que le suministraban desde la embarcación. Nació un nuevo deporte, el buceo autónomo, y se aceleraron vertiginosamente los descubrimientos de pecios a poca o media profundidad (entre 10-50 m), ahora casi míticos, como Metona (Bass, 1973), Albenga (Lamboglia, 1952) o el Grand Congloué (Benoit, 1961). Los arqueólogos entraron en acción para organizar la arqueología científica. Los países mediterráneos comprendieron la enorme responsabilidad que tenían y las posibilidades de la riqueza arqueológica de los fondos. En 1957 el Istituto Internazionale di Studi Liguri (Bordighera) fundó con Italia, Francia y España el Centro Sperimentale di Archeologia Sottomarina de Albenga y una publicación científica periódica, Forma Maris Antiqui. Se consideró primordial entablar relaciones de colaboración con pescadores y deportistas, para controlar las actividades y evitar el expolio, para lo cual se designó un Comité permanente para confeccionar una Carta Arqueológica del Mediterráneo, dotándolo de los medios necesarios. Fundado por Nino Lamboglia, por parte española formaron parte del comité de redacción, Martín Almagro, Pedro de Palol, Juan Maluquer, Luis Pericot, Eduard Ripoll, Miguel Tarradell y Francisca Pallarés. Otros reconocidos arqueólogos y militares potenciaron la arqueología submarina, Oliva, quien realizó la primera prospección de Cala Culip en 1954-55
(Oliva, 1958), y Ripoll (1961) en Cataluña; Beltrán Martínez y Sanmartín, junto al Jefe del Estado Mayor de la Armada, Jáuregui, al Almirante Bastarreche (Almagro Gorbea, 2008) en Cartagena, y al almirante Guillén, director del Museo Naval en Madrid. A partir de entonces las operaciones de los buceadores deportivos o de la Armada fueron dirigidas por arqueólogos desde la embarcación, como en los pecios de El Capitán (Mas, 1972), el Sec (Pallarés, 1972) o el Triunfante (Ivars, 2011).

\section{Arqueología Submarina}

Antes de continuar quiero aclarar la razón de mantener la antigua denominación submarina, en contra de la corriente en boga de utilizar la de subacuática. Es, entre otras cosas, simple y llanamente por tradición, que además de sabiduría implica respeto $\mathrm{y}$, sobre todo, porque mantenerla es una virtud marinera. A mediados del siglo $\mathrm{XX}$, se decidió llamar así, arqueología submarina, a la entonces casi recién estrenada arqueología. El bautismo viene de muy atrás, es una pequeña historia que conviene no olvidar. El tema se planteó con virulencia en las primeras reuniones sobre arqueología submarina durante los años 50 del pasado siglo. Es verdad que el agua que cubre los restos arqueológicos no siempre es salada, buceando se puede llegar, no solo al fondo del mar, sino al de lagos y ríos, embalses o, incluso, pozos, razón por la cual algunos de aquellos pioneros defendían que se debería designar subacuática. Hubo dos intentos de cambiar el nombre a la arqueología submarina, que se había ido adoptando desde su nacimiento digamos que naturalmente. El primero de ellos casi pasó desapercibido. El segundo, con motivo del IIoㅡ Congreso Internacional de Arqueología Submarina de 1958, celebrado en la ciudad italiana de Albenga (VV.AA., 1958). Fue abanderado por uno de los congresistas, D'Arrigo, quien propuso y planteó con firmeza el cambio de nombre, en un alarde de justicia para la arqueología que no se desarrollaba en la mar. Sin embargo, la cuestión se zanjó ante la opinión de una de las mayores autoridades del momento en estas materias, el pionero arqueólogo italiano Nino Lamboglia, que fue admitida casi unánimemente por respetar el nombre que se había venido utilizando desde el principio, sin perjuicio de que se realizase en agua dulce. Había una razón indiscutible la arqueología submarina había nacido en la mar. 
La denominación se mantuvo oficialmente en el área mediterránea al menos hasta el VI Congreso Internacional de Arqueología Submarina, celebrado en Cartagena en 1982 (VV.AA., 1985). A pesar de que la UNESCO, ya en 1973, había publicado un libro titulado Archéologie Subaquatique, une discipline naissante, en España se mantuvo su tradicional calificativo con la creación del Centro Nacional de Investigaciones Arqueológicas Submarinas (CNIAS) en 1980. Actualmente el término se va perdiendo, con honrosas excepciones (Almagro, 2008), se impone con fuerza el de subacuático. Sería interesante averiguar cuál fue el motivo del cambio oficial en España, porque nada es por casualidad, se puede sospechar un intento de ruptura con lo anterior debido a los cambios políticos. Lo cierto es que cuando el Ministerio de Cultura trasladó desde las instalaciones del Dique de Navidad al puerto de Cartagena el Museo y el Centro Nacional de Investigaciones Submarinas (2001-2007), le cambió también el nombre al museo, ARQVA Museo Nacional de Arqueología Subacuática (Real decreto de 2008). El Centro Nacional de Investigaciones Arqueológicas Submarinas (C.N.I.A.S.), conservó su denominación original, pero la palabra submarinas quedó enmascarada, porque este último siempre figura con sus siglas. Lo que resulta paradójico es que los mismos que prefieren el término de subacuático en todos los círculos, no solamente en el científico, a los buceadores les llaman submarinistas. Me pregunto qué les reservan a los tripulantes de un submarino.

En el arranque de la arqueología científica, España partía con grandes posibilidades, aunaba la riqueza de las costas con la cooperación de la Armada, que destacaba en el desarrollo de las técnicas del buceo, la dirección de arqueólogos y la colaboración de buceadores deportivos experimentados. Reflejo de ello es, que el III Congreso Internacional de Arqueología Submarina se celebrara en Barcelona con éxito en 1960 (Ripoll, 1961). Desde 1962, Martín Almagro, Comisario General de Excavaciones Arqueológicas dio un gran impulso a la arqueología submarina y promovió su articulación con la creación de los Patronatos de Excavaciones Arqueológicas en las Provincias Marítimas. En 1973 se celebraron las primeras Jornadas sobre Arqueología Submarina en Cartagena, presididas por el propio Almagro. La comisión de trabajo fue organizada por Julio Mas, con la participación de Eduardo Ripoll Perelló, Miguel Oliva Prat, Manuel Antonio Martín Bueno, Ricardo Pas- cual Guasch, Federico Foerster Laurea, Bartolomé Enseñat, José Mascaró Pasarius y Manuel Monzón Francés. Se creó el Patronato de Excavaciones Arqueológicas de la Provincia Marítima de Cartagena, posteriormente se fundaron el Centro Nacional de Investigaciones Arqueológicas Submarinas de Cartagena, del que procede el Museo Nacional de Arqueología Submarina (1980); el de Cataluña (Gerona), Centre d'Arqueología Subaquàtica de Catalunya, CASC (1992), único actualmente efectivo que cuenta con un elemento tan imprescindible para realizar investigaciones submarinas como es un barco, el Thetis; el de la Comunidad Valenciana (1996); y el Centro de Arqueología Subacuática de Andalucía en Cádiz, CAS (1997).

El grave problema de que en las excavaciones submarinas el arqueólogo se quedaba en tierra, mientras los buceadores llevaban a cabo las operaciones, se había planteado muy pronto. La profesionalización se imponía, aunque contábamos con ejemplos de muchos aficionados dedicados a la arqueología, que sin ser profesionales ni titulados universitarios eran verdaderos modelos a seguir: como Honor E. Frost o Peter Throckmorton y, en España, Federico Foerster, Juan Bravo, José Beltrán, Juan Ivars y Julio Mas, que se tituló en Historia posteriormente. La profesionalización permitiría entrar a formar parte de la ciencia arqueológica de pleno derecho y sacudir el calificativo de deportiva que arrastraba. Se imponía la formación experimental en ambas ramas, que por entonces estaba muy lejos de impartirse como enseñanza universitaria, mediante la colaboración en excavaciones arqueológicas y la realización del curso de buceo profesional. La Armada jugó un papel primordial en la profesionalización civil del buceo, el año 1970, el único centro en España que impartía cursos para la obtención del título profesional, era el recién creado Centro de Buceo de la Armada (CBA), en la Algameca, Cartagena (Vallespín, 1986b). A este respecto, en Cádiz, el año 1984, Ramón Corzo, director del Museo Provincial y José María Luzón, catedrático de Historia Antigua de la Universidad, se interesaron por la formación de estudiantes en la materia por lo que algunos de ellos asistieron en prácticas a las excavaciones submarinas que llevábamos a cabo en el pecio de El Aculadero de La Caleta (Vallespín, inédito).

La arqueología submarina ha arrojado una inmensa cantidad de datos de diversas épocas que, aunque a menudo se encuentra dispersos y son desconocidos por los investigadores, ofrecen una 
nueva perspectiva para los estudios históricos y dan sentido a algunas de las incógnitas y lagunas existentes. La muy diversa cronología de los pecios documentados proporciona una visión continuada de la navegación y contempla su desarrollo y el de los pueblos marineros desde la Prehistoria hasta nuestros días. Pero, qué es un pecio, la palabra pecio, para algunos desconocida, se utiliza mucho en español como en francés épave y en inglés shipwreck. La arqueología ha adaptado este evocador término pero, tal vez en su afán académico de encorsetar, le ha ido poniendo límites contrarios a su origen. Según el Diccionario de la Real Academia de la Lengua Española, pecio viene del latín pecium y significa, en su primera acepción, "pedazo o fragmento de la nave que ha naufragado o porción de lo que ella contiene y, en la segunda, derechos que el señor del puerto de mar exigía a las naves que naufragaban en sus marinas y costas". Es decir, que la palabra tiene una triple connotación descriptiva, jurídica y económica, debido a que cualquier resto que se hallare en el fondo, si tiene un valor pecuniario y posibilidad de ser rescatado, tanto si se trata de un ancla, de una cadena o de un cargamento completo, debería pagar un pecium. La extracción por esos motivos poco afines a los arqueológicos, dicho sea de paso, tiene una larga tradición que se remonta a épocas muy tempranas y es por ella, paradójicamente, por la que ha tenido tantos adeptos en arqueología la utilización de la palabra pecio para designar los yacimientos de las profundidades. Por ello, como término arqueológico su sentido está resultando equívoco, pues se ha venido estableciendo que la palabra pecio debe usarse para indicar exclusivamente un barco hundido determinado (VV.AA., 1988). El problema se plantea a causa de que a partir del primer contacto, cuando se descubren restos arqueológicos, en prospecciones sistemáticas principalmente, es muy difícil determinar si se trata de los restos de un barco, de varios o, incluso, si ni siquiera responden a una embarcación. Los términos descriptivos como campo de ánforas o cementerio marino, debidos al aspecto ofrecido por la primera impresión del descubrimiento, habían llegado a generalizarse en los informes de investigaciones submarinas y publicaciones, sobre todo en los de prospecciones. No se definen como pecios en sentido estricto de yacimientos arqueológicos los que no pueden ser identificados correctamente, bien por la excesiva amplitud cronológica de determinados materiales, bien por tratarse de objetos susceptibles de haber sido arrastrados por la corriente y agrupados accidentalmente o, por el contrario, debido a su amplia dispersión espacial y al propio estado de conservación. Pero se dan casos curiosos en los que en un primer momento un hallazgo, incluso realizado sistemáticamente, es interpretado y publicado como un barco aislado y, después de una o dos campañas de excavación, se obtienen pruebas para llegar a la conclusión de la existencia de más de un naufragio en el mismo lugar o de que se trate de un fondeadero. En otras ocasiones dos pecios que se encuentran a considerable distancia uno de otro, una estatua o un cañón aislado, han resultado ser los restos de un mismo barco roto en superficie por el temporal o por una explosión y disgregado después al caer al fondo con su carga. Objetos de culto o ánforas cercanas a la costa podrían formar parte tanto de un barco determinado como del derrumbamiento de una instalación terrestre, faro, templo o construcciones portuarias (Parker, 1992). Para mantener el rigor científico hay que tener en cuenta por tanto, aunque en muchas ocasiones la intención de la utilización del término pecio continúe siendo la de designar un barco hundido, que la realidad es que ha pasado a ser sinónimo de yacimiento. Si no queremos abandonar una palabra tan misteriosa y sujeta a la historia de la arqueología submarina, es necesario mantener un significado amplio, no olvidar su primera acepción, de que cualquier cosa, por muy insignificante que sea, tiene un valor arqueológico inestimable desligándolo del valor pecuniario.

\section{Prospecciones y excavaciones arqueológicas submarinas}

En Cádiz no se había hecho nunca un trabajo de este tipo hasta nuestra llegada, aunque habían sido numerosos los hallazgos en sus fondos marinos, los cuales nos orientaron a la hora de proyectar las prospecciones. El significado de la primera campaña fue una toma de contacto con Cádiz, sus costas, sus problemas y sus gentes. En ella delimitamos las zonas más sobresalientes arqueológicamente hablando: La Caleta y Sancti Petri (Vallespín, 1977). El objetivo inicial era inventariar los yacimientos sumergidos a partir de la documentación precedente, promover la colaboración de los buceadores locales y realizar prospecciones sistemáticas, con la finalidad de emprender la excavación en alguno de los pecios más apropiados y de ese modo, si no evitar, al menos disminuir la 
destrucción del patrimonio sumergido debida al expolio, al saqueo y a la general exposición a la fuerza erosiva de los elementos.

El medio marino en que se desarrolla la actividad es muy diferente al terrestre y la seguridad es uno de los factores más importantes a tener en cuenta. A lo largo de las campañas fue determinante adoptar las medidas generales de seguridad en buceo adaptadas a la mala visibilidad, corrientes y vientos fuertes. Gracias a Dios no tuvimos que lamentar ningún accidente de buceo en ninguna de las campañas realizadas. En general en Cádiz el agua es turbia por la cantidad de plancton en suspensión de las aguas atlánticas y, sobre todo, en el límite oceánico del caño de Sancti Petri porque los aportes y sedimentos son removidos por las corrientes, lo cual, aparte de dificultar la visibilidad (0,40-4 m) y la orientación, nos impedía una documentación fotográfica aceptable. Solamente cuando soplaba un levante suave el agua se aclaraba y, aun así, era difícil lograr una buena calidad, además de que las cámaras fotográficas no tenían la capacidad de las actuales. Aparte del peligro que suponen para la navegación, los temporales, siendo los de Poniente los más temibles, ocasionan continuos y profundos movimientos de arenas, que pueden cubrir por completo los pecios o dejarlos descarnados de la cubierta que los protege de un año para otro. Los caños son ríos de agua marina. En el Caño de Sancti Petri, las corrientes suelen ser fuertes, de hasta de 3 nudos. Oscilan dependiendo de la marea, cuando baja el sentido es hacia la mar ("vaciante") y cuando sube ("llenando") hacia el interior de la Bahía. Solamente en el poco tiempo del repunte de marea, apenas dos horas, se remansa y permite a los buceadores hacer un trabajo en condiciones. Dejando aparte el efecto erosivo que produce en los fondos, los de piedra, cascajo o arena no son buenos para la conservación de los elementos orgánicos, como las maderas de los cascos de los barcos, por el contrario, los de fango resultan muy apropiados para la conservación de los materiales arqueológicos sumergidos. Cádiz, por lo general, goza de otras condiciones muy favorables para bucear, cabe destacar, la poca profundidad y el agua templada. La plataforma continental desciende lentamente, de forma que cerca de la costa, donde se localiza la mayoría de los pecios, la profundidad oscila entre 10 y 25 m. En el Caño apenas se alcanzan los 6 m (10 con coeficiente alto de marea), lo cual permite inmersiones largas y sucesivas con poco consumo de aire y sin problemas de descompresión. Una de las dificultades añadidas en la labor de prospección estaba relacionada con la localización de los hallazgos, que realizábamos tomando rumbos con brújula de mano y marcaciones a tierra, por lo que no podía ser muy exacta. Hay que tener en cuenta que no contábamos todavía con GPS. Al principio señalábamos con boyas el lugar de interés cuando era necesario volver al día siguiente, pero las boyas desaparecían. Pensábamos que la boya representaba un valor en sí, así que para que no se la llevaran dejábamos una simple botella de plástico en vez de boya, pero al volver no estaba ni la botella ni el cabo. No se trataba de sabotajes, como hay quien ha supuesto. Optamos por no dejar nada para señalar, porque además hay que comprender que una botella de plástico que no se ve bien puede ser un peligro para la navegación. Ello nos obligaba cada vez a dedicar un rato más o menos largo a volver a localizar el sitio.

El resultado del estudio basado en la gran cantidad de datos de las prospecciones realizadas, tanto en Sancti Petri y como en La Caleta, como son los lugares que presentan un peligro para la navegación, abrigo y aguada, las noticias orales o escritas, la procedencia de los objetos extraídos (estuvieran depositados o en destino desconocido) y el expolio al que estaban sometidos los pecios añadido a la carencia de medios, aconsejaba que lo primero que se debía realizar era una carta arqueológica del litoral, para identificar, inventariar, situar y valorar el estado de conservación de los pecios. A partir de ese momento nuestras investigaciones se dirigieron a ese fin, con mayúsculas, elaborar una Carta Arqueológica Submarina de Cádiz, que sirviera en primer lugar para su defensa contra el expolio que sufrían los yacimientos sumergidos, dejando para más adelante la posibilidad de realizar un trabajo de excavación en un sitio concreto, que, aunque indiscutiblemente muy necesario también, precisaba de una mayor documentación del litoral y de una inversión y financiación que estábamos muy lejos de conseguir (Vallespín, 1985). Teníamos presente que la realización de una excavación no es un mero rescate de materiales. Frente a la prospección, la excavación conlleva la documentación del pecio, la extracción sistemática, la conservación de los materiales, la interpretación, la reconstrucción en su caso del barco y de la carga y la difusión de la intervención. La excavación no consiste en un mero recuento y estudio de materiales obtenidos, para llegar a eso 
nos podríamos haber evitado el camino recorrido. El motivo de la lucha contra el expolio es precisamente, erradicar la extracción de materiales arqueológicos sacándolos de contexto.

\section{Sancti Petri}

Como es sabido, partiendo de las fuentes antiguas y de los restos arqueológicos, algunos autores situaban y todavía sitúan el legendario Templo de Hércules, fundado en los albores del siglo XII a. C., bajo el castillo Sancti Petri, otros, en la orilla frontera de Retamar. Pomponio Mela, que era de Tingitera, Algeciras, nos transmite entre el año 43-44 d.C. en su Chorographia, que en el Templo se guardaban las cenizas del propio Hércules (García y Bellido, 1947). Así en el Templo estaba la tumba de Hércules, como en el Vaticano la de San Pedro. Lo pone de manifiesto los restos arqueológicos documentados y el que todavía en la Cádiz hispanomusulmana quedara el recuerdo, a través de referencias escritas, de la existencia de un fantástico monumento de más de 60 metros de altura relacionado con la tumba de Melqart (Almagro-Gorbea, 2013).

La pregunta que surge es cómo y por qué desapareció casi sin dejar rastro tan fastuoso templo y de tal arraigo. ¿Por qué los hallazgos relacionados con él han sido descubiertos por debajo del nivel actual del mar? Las palabras del geógrafo Avieno, de finales el siglo IV d.C. en su obra Ora Marítima, nos transmiten que Cádiz "nunc ruinarum agger est" -"ahora es un montón de ruinas"- (Gavala y Laborde, 1959). La investigación actual, además de atender a los múltiples factores que pueden haber incidido, como el análisis de las antiguas líneas de costa derivadas de fluctuaciones por el clima y fenómenos ambientales costeros, de regresión y transgresión, excavación, colmatación y subsidencia, de acuerdo con las últimas tendencias, debe tener más en cuenta los bruscos cambios producidos por violentos movimientos sísmicos. Hay elementos arqueológicos, además de los documentales, que ponen de manifiesto, que el puerto de Sancti Petri perduró incluso hasta finales del siglo IV y posteriormente, bajo dominación musulmana (Gallardo et al., 1995; Vallespín, 2000).

El topónimo Sancti Petri está compuesto por dos palabras en genitivo singular latino. Tanto puede referirse a la isla, como al caño o al poblado, que serían de San Pedro. Probablemente, porque así está atestiguado, el topónimo derive de que en el islote había una iglesia dedicada a San Pedro, que fue mártir, crucificado cabeza abajo por Nerón (54-68 d.C.). Recordemos el letrero de la cripta en la Basílica del Vaticano de la tumba de San Pedro: SEPULCRUM SANCTI PETRI APOSTOL. En el siglo V d.C. se extiende la veneración de las reliquias sagradas de los mártires y la exposición a la vista de los fieles en determinadas fechas o en relicarios en las basílicas y santuarios. Se podría aventurar que en la iglesia del islote se guardaran reliquias del santo apóstol. Gerónimo de la Concepción en su Emporio del Orbe (1760) atribuye a la tradición que "fue el apóstol Santiago el que rebautizó el lugar como Sancti Petri, de San Pedro, ya que era costumbre por entonces renombrar los grandes santuarios de la antigüedad con nombres propios del cristianismo". El culto a San Pedro se fue extendiendo desde muy pronto en España, relacionado con el agua, el paso de los ríos o como protector de los pescadores y custodio de las llaves del cielo. Las iglesias bajo la advocación del apóstol datan de edad muy temprana. Entre las más antiguas destaca San Pedro de Roca en la Ribeira Sacra (Orense), monasterio excavado en la roca fundado por eremitas suevos, que data del 573 pero que ya fue espacio de culto desde época prerromana (Ruíz, 2011). San Pedro de la Nave, templo visigótico situado en la ruta de la Plata, estaba dedicado a los barqueros San Julián y Santa Basilisa, manifestado en uno de los capiteles del interior del templo en el que se representa una deliciosa nave. El cruce del río Esla que facilitaban los santos barqueros, se puede comparar con el del caño de Sancti Petri por la vía Hercúlea del Itinerario de Antonino. Hay referencias del paso por medio de una barca (Landes Industries, 1820), que incluso dio nombre a la península donde hoy están las ruinas del poblado almadrabero, la Barca de Sancti Petri. Muy característico, relacionado con la navegación y las reliquias del Apóstol, es San Pedro de Roda en el Cabo Creus. El año 610 los fundadores de la iglesia arribaron después de una travesía en barco desde Roma, trayendo consigo reliquias de San Pedro, que enterraron en la cripta bajo el altar. Habría sido una línea de investigación interesante averiguar si también se guardaron reliquias del apóstol en la iglesia de Sancti Petri. Lo que sí se puede asegurar es que la iglesia dedicada a San Pedro que había en el islote, aunque desconocemos la fecha de la fundación, fue una iglesia mozárabe que perduró durante toda la ocupación islámica y el cristianismo en la Alta Edad Media, tal y como 
las fuentes árabes se ocuparon de transmitirlo en diversas ocasiones hasta el siglo XV, "en Sant Baytar (Sancti Petri) hay una iglesia muy venerada por los cristianos" (Molina, 1983). En el siglo XVII aún perduraba una ermita en el islote (Suarez, 1610), de la cual tenemos una imagen (Figura 1) representada en el grabado del asalto a Cádiz por la flota anglo-holandesa en 1596 (Fernández, 1973; Martínez et al., 2000) y que sucumbió con la construcción del fuerte en el siglo XVIII, pero en cuyo interior posteriormente se le dedicó una capilla (Vallejo, 1812). El culto a San Pedro pescador pervivía esmaltado en azulejos, en la fachada de la iglesia del poblado de pescadores de la almadraba de Sancti Petri, una sencilla imagen de San Pedro con un atún cruzado. En cambio, si nos atenemos a los reclamos turísticos actuales, el verdadero significado de Sancti Petri sería "piedras santas" en recuerdo del santuario dedicado a Melkart.

\section{Campañas iniciales}

A finales de 1972, Máxine Asher, M.A., profesora de ciencias sociales y directora de la Ancient Mediterranean Research Association (AMRA) de Los Ángeles, California, con el patrocinio de la Universidad de Pepperdine Summer Research Program y, a través del profesor de la Universidad de Sevilla, José María Luzón, inició un proyecto de investigación sobre el Origen cultural común del antiguo mundo mediterráneo, a llevar a cabo entre el 9-17 de agosto de 1973. El proyecto, además de actividades culturales y turísticas, incluía una expedición submarina para buscar la Atlántida en aguas de Cádiz. Reunía un grupo multidisciplinar de científicos para investigar sobre una Atlántida diferente a la de la mitología clásica, según afirmaba su directora, con un grupo de especialistas, Gabriel DeCicco, codirector, William R. Shell, director de Media Production, Mesa-Spring, del Valley School District, y Jack Blake, asistente al director y Bill Ferrer, del Audio-Visual Instruction San Diego City Schools. Entre los especialistas contaban con Edgerton Sykes, profesor de Historia, y Bruce Rosendhal, oceanógrafo de la Universidad de San Diego, California, que basaba el proyecto de prospección en la subida del nivel del mar en el sur de España hace 10.000 años. Junto a ellos un nutrido grupo de estudiantes jóvenes y estudiosos de edades dispares, que se alojarían en el Isecotel y que recibirían clases sobre la historia y cultura de la Atlántida en el conservatorio Manuel de Falla y clases de buceo. Lo mejor fue que entre las personas del grupo de todo tipo, personajes, intelectuales, cineastas, destacaban buceadores de la categoría de Jacques Mayol, el "hombre delfín", que batió marcas de profundidad en apnea (60 m. en 1966 y 105 m. en 1985), Francisco Salazar Casero, más conocido y admirado en Cádiz como el "Pantera". Como director de las prospecciones arqueológicas submarinas, Julián Nava, profesor de Historia de la Universidad Northridge de California y yo misma, como directora de la parte española, en calidad de arqueóloga y buceadora profesional.

El grupo llegó a Cádiz según lo previsto, iniciándose las actividades culturales. La situación de la

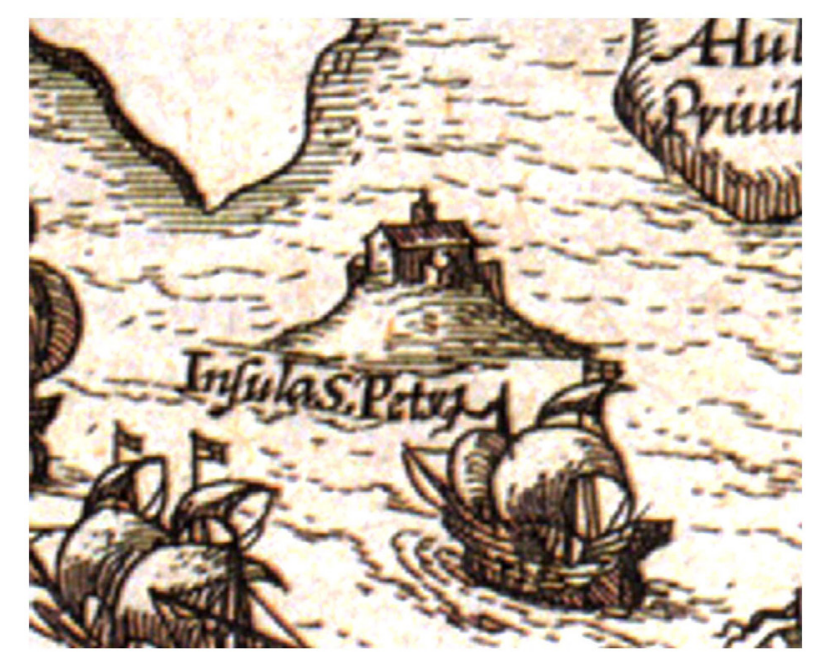

Figura 1. Iglesia de San Pedro en el islote de Sancti Petri, detalle del grabado del ataque de la flota angloholandesa a Cádiz, 1596. (Fuente: Martínez y Barros, 2000). 
expedición se iba complicando, al no hacer acto de presencia el director de la prospección arqueológica por parte de AMRA, Julián Nava, y la falta de concesión por parte de la Comandancia de Marina, que tenía la competencia sobre las aguas territoriales para llevar a cabo las inmersiones (M.C., 1973). El anuncio a bombo y platillo de que la expedición AMRA había descubierto en aguas internacionales, a 14 millas de la costa y $25 \mathrm{~m}$ de profundidad, restos de una civilización relacionados con la Atlántida, mostrando dibujos de tambores de columnas, bloques de piedra, pavimentos de 25 metros de largo y unos cuellos de ánforas, además de fotografías realizadas por William Farrell y Barry Seas, precipitó el fracaso de la expedición. Desde la Comandancia de Marina llamaron a consulta a la directora, que, cuando recibió el aviso, sacó precipitadamente un billete de avión para Irlanda, lamentándose porque el proyecto podía haber sido algo muy bonito y dejando abandonado al grupo expedicionario incluidas sus propias hijas. Previamente Julián Nava, había renunciado por carta a la dirección sin comunicar nada a la Dirección General de Bellas Artes. La noticia del gran descubrimiento, que por supuesto era falsa, pretendía hacerse con la opinión pública para conseguir el permiso del Ministerio de Marina, pero había sido precisamente esa noticia el motivo de la citación por el Comandante de Marina. La verdadera causa del fracaso de la expedición del AMRA quedó oculta, pero lo cierto es que las fuertes tensiones que se produjeron por las opiniones de las fuerzas vivas locales, la Directora del Museo, el Gobernador Civil, el Gobernador Militar, el Comandante de Marina, los Presidentes de asociaciones de buceo, medios de comunicación local y la opinión pública, condujeron a la desautorización y a la negación del preceptivo permiso de la Comandancia de Marina. Al final se desequilibró la balanza y todo concluyó sin que se iniciara la prospección, bien es verdad que sin la mínima inversión por parte del gobierno de España. Según declaraciones de algunos de los miembros de la expedición, el objetivo principal era filmar una película documental submarina científica de acción, como al final se ha realizado muchos años después (Cameron et al., 2018).

Fue el primer contacto con Cádiz. Me dio la oportunidad de conocer a personas que me enseñaron y me apoyaron para emprender la primera campaña de prospección submarina: la Directora del Museo Provincial de Cádiz, Concepción Blanco, la entrañable "Doña Concha" -en el mundillo-, el
Jefe de Estado Mayor, José Pettengui Estrada, el Teniente Coronel Agustín Moreno Páramo y una persona excepcional, Francisco Salazar Casero. Quien como buen conocedor de los fondos gaditanos y entusiasta de Tartesos, me fue introduciendo en la órbita de la arqueología no oficial, comunicándome de palabra y mostrándome debajo del agua sus hallazgos en la costa, Matalascañas, Chipiona, Cádiz y Sancti Petri (Figura 2).

La primera campaña con los objetivos previstos significó una toma de contacto con el litoral gaditano. El día 7 de agosto de 1973 dimos por iniciada la campaña que fue autorizada y subvencionada por la Comisaría General de Excavaciones Arqueológicas, de la Dirección General de Bellas Artes del Ministerio de Educación y Ciencia, con la cantidad de 10.000 pts. Martín Almagro Basch, quien continuaba demostrando un decidido interés por impulsar la nueva rama submarina de la arqueología y tenía ideas claras para llevar adelante su desarrollo apoyando iniciativas concretas. Comenzó con la organización de los primeros colaboradores, todos buceadores profesionales capitaneados por Francisco Salazar, que formaban su propio equipo de Astilleros Españoles: Francisco Porras, Antonio Rodicio, Juan Jaén, José Lanillo, así como los tripulantes de la pequeña embarcación el "Rosita Baro", los hermanos José y Manuel Cepero.

En Sancti Petri, en el entorno del islote, se contaba con numerosas noticias de restos arqueológicos relacionados con el templo de Hércules, documentados desde el siglo XVIII (García y Bellido, 1964a, 1964b). Esculturas, monedas y la propia estructura del Templo, en particular dos columnas, avistadas con las grandes bajamares que se sucedieron en 1730 y 1731 y después del terrible terremoto de Lisboa de 1755, en que se recogieron en la playa diversas estatuillas. En 1905, a 10 m de profundidad, entre el bajo Munerano (para el autor sería el Moguerano) y la isla, un buzo clásico relató la existencia de graderías y escalones y extrajo una figurita de Attis de bronce y una escultura acéfala de mármol, que hoy está expuesta en el Museo Provincial. En 1925, cuando se voló el escollo Rompetimones, los buzos localizaron a $2 \mathrm{~m}$ de profundidad gran cantidad de pedazos de plomo con sillares labrados, partes de escultura de bronce "cuyo pie está sumergido en una informe masa de plomo". Se encontraron sillares unidos con grapas de plomo que formarían un basamento cilíndrico de $3 \mathrm{~m}$. de diámetro y estimaron que la estatua debía medir unos $4 \mathrm{~m}$ de altura. La es- 


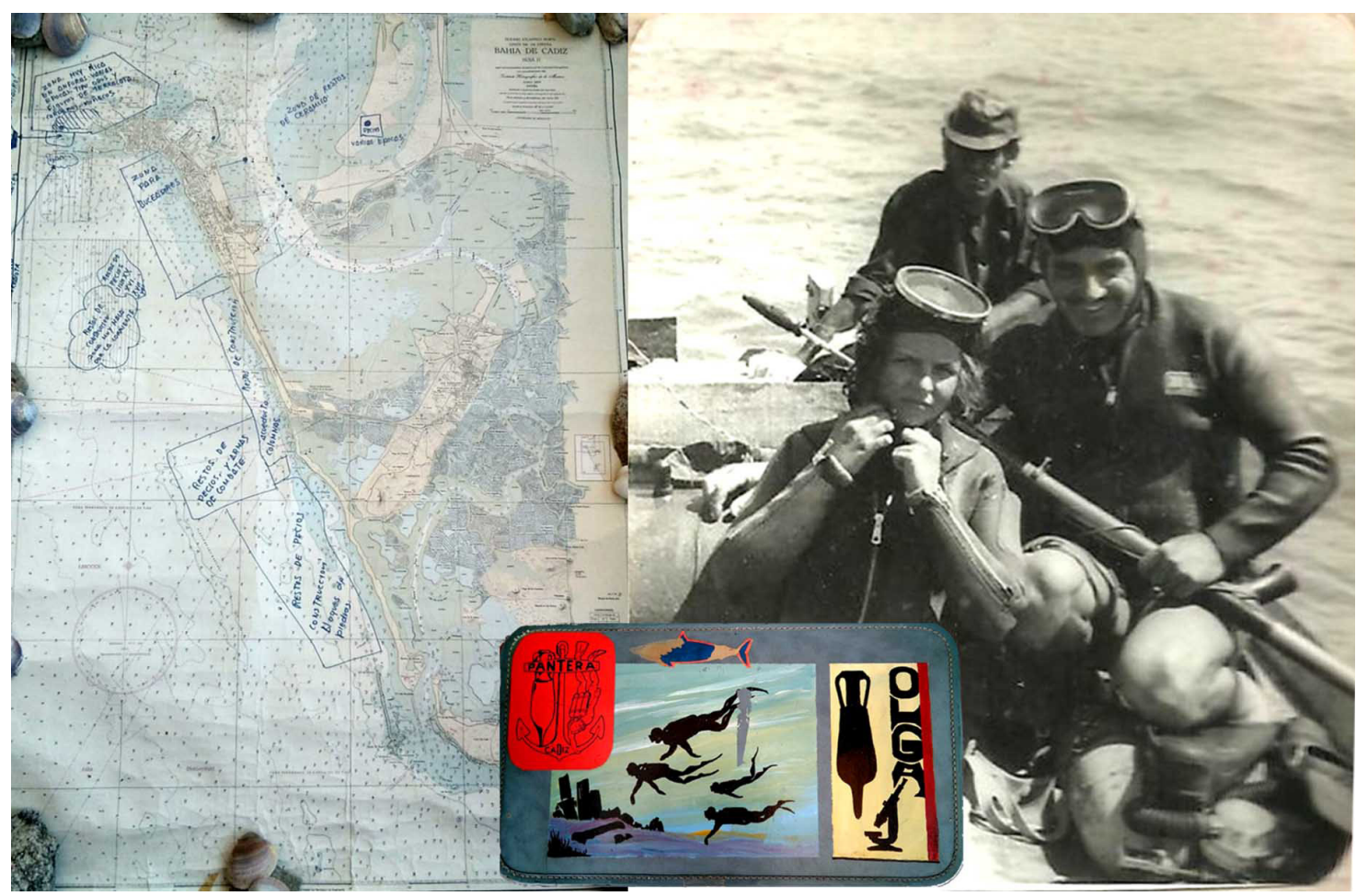

Figura 2. Izquierda: Carta de pecios de F. Salazar. Derecha: F. Salazar, O. Vallespín y Cepero en Sancti Petri, 1973. Centro: Ilustración de F. Salazar sobre maleta.

tatua, recompuesta y restaurada con coraza y un brazo extendido también se conserva en el Museo Provincial de Cádiz. En 1934, aunque se desconocen las circunstancias, se hallaron dos pequeñas figuras de conejos que de una colección particular ingresaron en el Museo. Por otra parte, según las referencias de Francisco Salazar, al norte del Arrecife del islote próximo a la Ahogada, a $6 \mathrm{~m}$. de profundidad había hallado, grandes bloques de roca cúbicos, que parecían restos de construcción y, al sur del canal del Boquerón, a $2 \mathrm{~m}$. de profundidad, en fondo de arena restos de construcción. Frente al coto de San José a $3 \mathrm{~m}$ de profundidad, así como en el estuario del Caño señalaba diversidad de restos que parecían arrastrados por la corriente. Otras referencias situaban restos de calzada "iguales a los que se podían ver en la playa de Cádiz", sumergidos al oeste del islote de Sancti Petri, donde se suponía que se metía en el agua, y "se ven losas aparejadas en hiladas, formando una especie de hongos por haber socavado el mar su base" (García y Bellido 1964a, 1964b).

La primera salida la realizamos desde el muelle de piedra de los pescadores, al este del poblado, el día 15 de agosto de 1973. El poblado almadrabero, que ocupaba el extremo de la península, entre el caño Alcornocal y el de Sancti Petri, había sido desalojado. El Consorcio Nacional Almadrabero había cerrado por falta de atunes, según nos dijeron. El pueblo estaba casi vacío, solamente el bar, de fachada achaflanada con arcos y soportales, continuaba abierto. En una explanada, cerca de la orilla del caño de Sancti Petri reposaban una cantidad enorme de anclotes de hierro de calar las redes de la almadraba. El gran edificio de la fábrica de los atunes, la "chanca", estaba cerrado. Había un muelle de madera y hormigón sobre el caño de Sancti Petri y, muy próximos, dos grandes barcos de la almadraba marrones y negros permanecían varados en la playa. En el muelle de pescadores del caño Alcornocal, donde se hallaban fondeados y amarrados unos cuantos pesqueros, embarcamos en el "Rosita Baro", con los hermanos Cepero, los "Mellizos", de tripulantes (Figura 2). El Caño discurría entre esteros y marismas comunicando la Bahía y la mar abierta, con apenas algunas embarcaciones. La orilla de Retamar, desierta, entonces zona de seguridad militar, conservaba antiguas baterías y estaba flanqueada por altas dunas de arena clara con algo de vegetación. Los areneros faenaban en el placer de arena situado ante la punta del Boquerón. Al fondo del estuario, la punta de Las Piedras, alargada por un rompeolas de rocas irregulares bastante reciente, estrechaba el paso 
por babor frente a la Punta de Poniente. Entre la punta de Las Piedras y el islote se hallaba un escollo, antes de que lo volaran, el Rompe Timones (Rompetimones). Fuera del caño, se recortaba el islote de Sancti-Petri, la torre cuadrada del faro del siglo XVI se alzaba en el lado norte, incorporada a una fortificación del siglo XVIII abandonada que se desmoronaba. La muralla del lado sureste estaba derrumbada, en los planos de 1737 y de 1840 ya hay referencias a estructuras ruinosas en ese punto. Al sur, separados del islote, se alzaban como verdaderos faros de piedra, los Farallones, el Grande y el Chico. Hacia el NNW rompían las olas al chocar con una barrera de roca, el Arrecife, plano y estrecho, que rectilíneo alcanzaba más de $1,50 \mathrm{~km}$ de longitud y cuyas grietas laterales, vistas desde el barco, semejaban enormes bloques de aristas rectilíneas cortadas artificialmente. Entre el Arrecife y la costa, en el canal del Boquerón de muy poco fondo, asomaban varios bajos, La Redonda, Trabuco y Moguerano, rocas oscuras que parecían construcciones derrumbadas por un cataclismo, camufladas por concreciones marinas y algas. Rocas formadas por conglomerados conchíferos pliocénicos, que en Cádiz se conocen como piedra ostionera o cangrejera (Gavala y Laborde, 1959). Como resultado de las inmersiones efectuadas, revisamos y documentamos, unos $300 \mathrm{~m}$. al sudeste del islote y a $6 \mathrm{~m}$. de profundidad, un talud tallado en la roca cangrejera sin juntas, de alrededor de 2,50 m de altura y de $50 \mathrm{~m}$ de longitud en sentido NE-SW, que podría estar relacionado directamente con construcciones portuarias de época fenicia (Figura 3) .

En 1974, se creó el Patronato de Arqueología Submarina de Cádiz, dependiente del de Cartagena, dirigido por Julio Mas, integrado por 60 personalidades poco más o menos, que particularmente solo nos creó problemas puesto que ofrecer por el momento no ofrecía nada. Nos supuso trabas burocráticas y un laberinto de gestiones, con la autorización de Bellas Artes ya no era suficiente. Para conseguir el permiso de la Comandancia de Marina, tenía que solicitarlo por escrito al Presidente del Patronato, ostentado por el Gobernador Civil, quien me contestaba por correo a mi domicilio, pero como ya me había trasladado a Cádiz, no me llegaba la contestación. El asunto se complicaba hasta el punto de que me enteraba por los periódicos de que la Marina me había concedido el permiso, porque la contestación del Gobernador Civil, siguiendo los cauces normativos, era remiti- da al Delegado de Educación y Ciencia de la provincia. Éste, a su vez, se la debía enviar al Patronato de Arqueología Submarina, cuya secretaria en esas fechas estaba de vacaciones. La Secretaría del Patronato directamente al propio Comandante de Marina.

Al principio solo contábamos con un bibotella, un regulador y dos trajes de neopreno. Era preciso como mínimo conseguir dos bibotellas, o monobotellas, 1 brújula submarina por buceador, una de superficie, profundímetros y una cámara fotográfica submarina, imposible de adquirir en las tiendas de la localidad. Pero lo fundamental era la embarcación, hicimos todo tipo de intentos para obtenerla sin éxito, ni de la Unidad de Operaciones Especiales del Tercio Armada de San Fernando, ni del grupo Juvenil de la OJE, ni de otras asociaciones deportivas, ni de Francisco Salazar, porque la suya la necesitaba para trabajar y por la misma razón no podía salir a diario con nosotros. Intentamos alquilar un bote a la limpiadora del Museo Provincial, al Club Náutico, al Bar Rincón, al Club Caleta. Llegamos hasta Chiclana y a Sancti Petri, el poblado lo habían vendido y no había pescadores, uno de los hermanos Cepero nos dio la dirección de alguien que podría alquilarnos su barco, el Comandante de Marina también intentó ayudarnos. Por fin, en la misma Caleta, Manuel Marchena, nos alquiló el suyo, el "José Alcántara", motor de bancada, 5,35 m de eslora 2,50 de manga. Astilleros Españoles, a través Francisco Salazar (que me regaló un pequeño bibotella hecho por él mismo y un regulador bitráquea), nos prestó los bibotellas que necesitábamos y se comprometió a llenarlos de aire comprimido a diario. El coronel del Castillo de San Sebastián, Ory Cristelly, nos presentó a su hijo y otros jóvenes buceadores interesados en participar, nos facilitó pases al castillo para los miembros del grupo, una habitación cerrada y agua dulce, que utilizamos de base en tierra en esa y en las siguientes campañas. Los nuevos miembros, José María Fernández Bastarreche, Rafael Ory, Adolfo Bosch Lería, Antonio Muñoz Gaviño y Pedro Utrera, todos buceadores excepto Pedro, aportaron además de sus propios equipos de inmersión una máquina fotográfica submarina. La subvención de Bellas Artes (50.000pts.) no había llegado, pero por la gestión de Pedro Valdecantos, Delegado Provincial de Cultura obtuvimos la concesión de 20.000 pts., gracias a las cuales pudimos arrancar. Nos marcamos unos objetivos muy ambiciosos, continuar la prospección submarina visual 


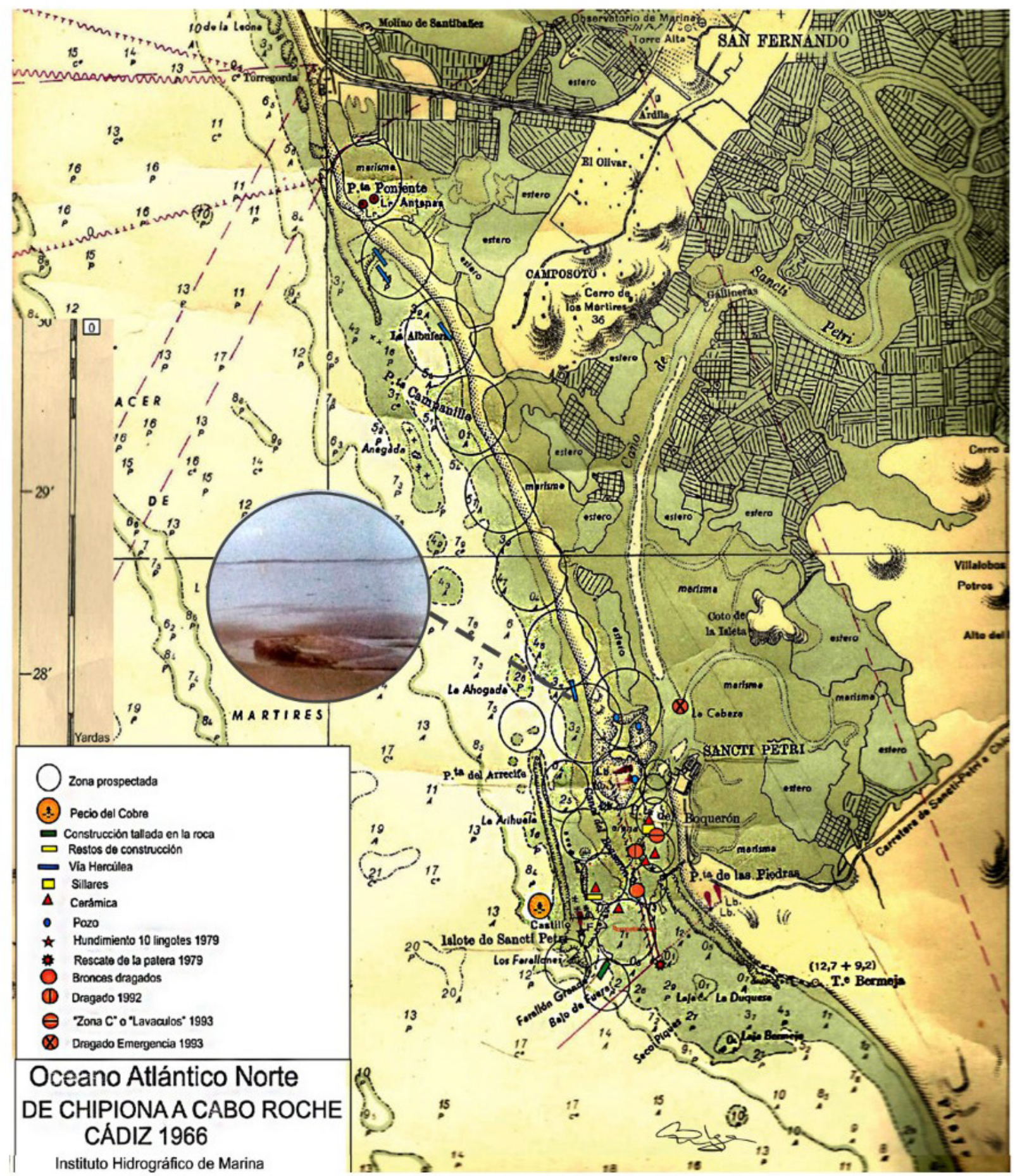

Figura 3. Carta Arqueológica desde La Albufera a Sancti Petri, 1973-79.

Revista Atlántica-Mediterránea de Prehistoria y Arqueología Social 22, pp. 281-308 
de La Caleta y de Sancti Petri. Por lo que respecta a Sancti Petri, en particular el canal del Boquerón y los bajos, el Moguerano, La Redonda, Trabuco, el área del desparecido Rompetimones, Morenatos y la punta del Arrecife. Y aprovechar los días que el mal tiempo o cualquier otra circunstancia que no nos dejara salir a bucear, para efectuar rastreos complementarios de campo o playa en el islote, el castillo de Sancti Petri y la punta de Retamar, con vistas a localizar restos de la Vía Hercúlea y su relación con el Arrecife. Y por supuesto, el estudio y análisis de las fuentes documentales, históricas y arqueológicas.

En esta campaña de 1974 nos volcamos en La Caleta, reduciendo los objetivos previstos porque Sancti Petri, tan apartado de Cádiz y con pocas comunicaciones, representaba un problema. Solamente prospectamos la vía por tierra, desde la plaza de toros donde se sitúa un miliario (Moreno, 1970), que no localizamos pero sí se podían ver dos alineaciones que entraban en la playa con un ángulo de 20 grados. Como no buceamos en el lugar, no pudimos valorar si se trataba de la vía romana o de arrecifes naturales. Seguimos por la playa con marea baja por la arena húmeda en un coche ligero, modelo mehari. Al sur de Cortadura eran perfectamente visibles los singulares restos de calzada, muy alejados del clásico modelo vitruviano. Dos parapetos paralelos de mampostería de piedra cangrejera de casi $0,50 \mathrm{~m}$ de anchura, $1 \mathrm{~m}$ de altura y de algo más de $6 \mathrm{~m}$. de longitud, se alzaban sobresaliendo de la arena, que ocultaba cualquier resto de pavimento, y otros tramos caídos y semienterrados, ya documentados con anterioridad (Pemán, 1949, 1954). No se hallaron columnas $\mathrm{u}$ otros indicios que testimoniaran que se tratara de una vía porticada. Este tramo fue identificado por investigaciones posteriores con el efímero Arrecife Nuevo borbónico (1735-1745), destruido por el terremoto de Lisboa de 1755. De factura dieciochesca, pero fiel al modelo romano, seguía un trazado prácticamente superpuesto a la Vía Augusta, denominada camino del Arrecife (del árabe ar-rasif, calzada), cuya estructura original se había mantenido en puntos concretos con sucesivos arreglos. En la Casa o Venta del Gallego (Figura 3), entre las dunas, registramos el otro tramo considerablemente largo con los parapetos sobre el pavimento, que en esta ocasión se hallaba descubierto por su extremo sur. La estructura de la vía aparecía cortada transversalmente, dejando a la vista su estratigrafía sin necesidad de excavar.
Comprobamos que en este punto conservaba el pavimento romano. Posteriormente, en 2004, las obras del EDAR de Cádiz a San Fernando seccionaron literalmente por su parte central este tramo conservado de vía de más de $200 \mathrm{~m}$, lo que motivó una denuncia por expolio formulada por Adolfo Bosch (Vallespín, 2004). Desde ese punto ya fue más difícil seguir porque el paso estaba prohibido por la instalación de Marina que había en Torre Gorda, el campo de tiro y el C.I.R de Camposoto. Pudimos atravesar por un camino de tierra, pero sin poder acercarnos a la playa porque se estaban efectuando prácticas de tiro. Sin embargo, Pedro Utrera, nos señaló unas antenas donde aseguró que la vía se sumergía en el agua. Unos días después, previa autorización y consejos de Eliseo González Mosquera, Jefe de Flotilla de Aeronaves, para que pudiéramos prospectar la vía sin peligro en el campo de tiro militar, volvimos al lugar indicado con los equipos de buceo desde La Caleta con el José Alcántara, tripulado por Manuel Marchena. Fondeamos en La Albufera enfrente de las antenas y revisamos visualmente la playa entre la punta de Poniente y el Corral de Vives, donde un arrecife apenas sobresaliente protege la playa (Figura 3). Realizamos la prospección con dificultad, porque pese al metro y medio escaso de profundidad había muy mala visibilidad, debido a que el fondo era de fango, y por el peligro de que pudiera haber proyectiles sin estallar. El arrecife de piedra cangrejera, también nos llevó a confusión porque las losas preparadas para extraer se semejaban las de un pavimento, a causa de que presentaba en la parte superficial marcas rectilíneas como de sillares y vaciados de extracción de bloques, generalmente rectangulares de roca y a veces de gran tamaño, canaletas de una antigua cantera abandonada. Localizamos restos de vía ya dentro del agua, apenas 1-1,50 m de profundidad, consistentes en varios muros de mampostería desplomados, semejantes a los de la playa de Cortadura y Torregorda, cubiertos de un fango gris muy fino y resbaladizo. Solamente pudimos reconocer el lugar exacto donde se sumerge y la dirección que seguía paralela a la orilla, en sentido al Arrecife.

En la siguiente campaña, llevada a cabo entre los días 2 y 29 de septiembre de 1975, el Ministerio de Educación y Ciencia, a través de la Dirección General de Bellas Artes, autorizó la realización las prospecciones y las patrocinó con una subvención de 100.000 pts., que junto a una asignación por parte del Presidente de la Diputación, Antonio 
Barbadillo, nos permitió finalizar la campaña. Pero la obtención del permiso de Marina para iniciar las prospecciones seguía complicada, como el año anterior desde la creación del Patronato de Arqueología Submarina de Cádiz.

El grupo de colaboradores se mantuvo, incorporándose dos nuevos voluntarios, Gabriel Mourente, buceador, y Mercedes Vallespín, dibujante, Licenciada en Bellas Artes. Manuel Marchena, el patrón, que había remozado el José Alcántara y comprado una patera, lo cual facilitaba el embarque de equipos, dejó su trabajo durante ese mes para salir con nosotros (1.000 pts. día) y así pudimos iniciar la jornada por la mañana. Los buceadores fallaban por cuestiones laborales o particulares, algunos días no éramos más de tres además del patrón, que solamente realizaba alguna inmersión ocasionalmente cuando era necesario, aunque era buceador y buen conocedor de los fondos de La Caleta, pues fue quien descubrió y entregó el famoso vaso trípode datado en el siglo VII a.C. (Thymiaterion) en el Museo Provincial (Blanco, 1970). Los problemas económicos llegaron a estar a punto de frustrar la expedición, no solo debido a la precariedad de la subvención, sino más bien al retraso en el cobro. El día 14 no trabajamos porque ya no nos quedaban ni 20 duros, no podíamos pagar las deudas contraídas, entre otros con el patrón, estuvimos a punto de cerrar la campaña. Pero, gracias a que mis padres me hicieron un préstamo inmediato, y a la Diputación, que poco después nos hizo efectivo el dinero concedido semanas antes, pudimos continuar.

Dedicamos poco tiempo a Sancti Petri y, precisamente el día 9 de septiembre de 1975 en que pudimos ir, no era el mejor día porque hacía viento sur y el agua estaba muy turbia, apenas había dos palmos de visibilidad. Adolfo Bosch y yo reconocimos el bajo Moguerano, a pulmón a 2 o 3 $\mathrm{m}$ de profundidad. A veces parecía que se podían identificar sillares, pero otras veces parecía simple roca cangrejera, que se erosiona por debajo cayendo en lajas rectangulares (Figura 3). Debajo del Moguerano localizamos un pecio de ladrillos contemporáneos, con marcas epigráficas: VILL y TE. El bajo estaba totalmente cubierto por organismos marinos que impedían reconocerlo, pero a simple vista no parecía artificial. Hay que añadir que la poca profundidad de los alrededores indica que es imposible la identificación de este bajo con el Munerano, en el que en 1905 se recuperaran a -10 m. el Attis y la estatua de mármol masculina acéfala (García y Bellido, 1964a, 1964b). José María F. Bastarreche y Gabriel Mourente, con botellas rastrearon paralelamente la zona al este del Arrecife, desde el bajo Moguerano hacia la punta del Arrecife, sin alcanzarla. La intención era atravesar todo el canal entre la playa de Retamar y la isla de Sancti Petri con vistas a localizar la Vía Hercúlea, pero no localizaron nada de interés. Mediante una prospección a pie sobre el mismo Arrecife, documentamos canaletas de extracción de losas rectangulares con diversas dimensiones, 2,80, 1,45, $1,60 \mathrm{~m} \times 1$ y $1,20 \mathrm{~m}$, concretamente una, de 1,60 x $0,95 \mathrm{~m}$., presentaba en la parte superior una cruz griega grabada perfectamente visible a pesar de estar cubierta por concreciones marinas; algunas triangulares y una semicircular de 0,85 x 0,50 m. En algunas partes localizamos vaciados de diversos tamaños, desde $10 \mathrm{~m}$ llegaban a alcanzar los $70 \mathrm{~m}$. de longitud N-S, los cuales parecían estanques porque se hallaban llenos de agua aún en bajamar. A través de fotos aéreas, tomadas por la colaboración de Eliseo González Mosquera, Jefe de Flotilla de Aeronaves de Rota (Figura 4), se mostraba muy claramente hasta qué punto, como tantos otros arrecifes de las costas de Cádiz, había sido explotado como una gran cantera de piedra cangrejera, lo cual llevaba a interpretaciones erróneas sobre la posibilidad de tratarse de una calzada monumental. Para su análisis histórico hay que tener en cuenta la transformación de la topografía del Arrecife como consecuencia de la extracción de piedra, hasta qué punto habrá modulado su fisionomía desde la Antigüedad. Por otra parte, algunas grietas geológicas profundas, que irradian desde un sector centrado en el borde occidental del Arrecife, parecen indicar un movimiento sísmico que habría llegado a quebrar en un momento dado el roquedal. Estas grietas y el aspecto de los bajos del canal del Boquerón, unidos a la situación de los restos arqueológicos encontrados bajo el nivel del mar con signos de derrumbamiento y de calentamiento, como son las piezas de plomo derretido por el calor, podrían indicar hubieran sido producidos por movimientos sísmicos. Además del conocido Terremoto de Lisboa de 1755, se han documentado bastantes terremotos y maremotos de gran magnitud, como el de 1504 que dejó enormes grietas en el terreno y en las murallas del Alcázar de Carmona y que repercutió en un área muy amplia (Bonsor, 1918). En Portugal en el 392 se produjo un maremoto, cuyo epicentro se ha fijado en el golfo de Cádiz, que afectó a Portugal y 


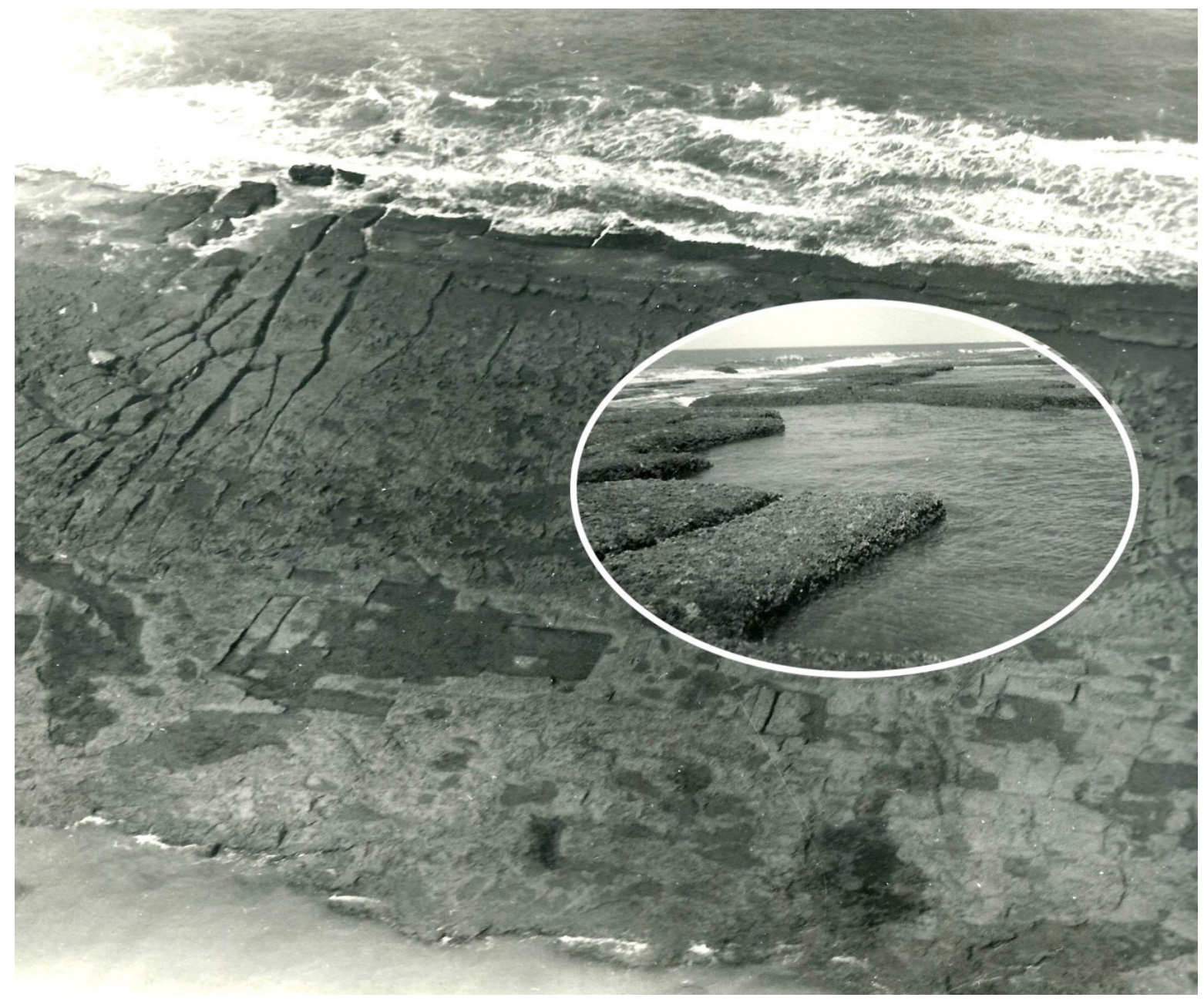

Figura 4. 1. Vista aérea del Arrecife, 1976. (Fuente: Flotilla Aeronaves de Rota); 2. Antigua cantera del Arrecife, 1976.

Andalucía y que tuvo como consecuencia la desaparición de unas islas frente al cabo de San Vicente (Sánchez-Navarro, 1932). Martínez Santa-Olalla ya interpretó como destrucción repentina la de un edificio de Carteia y aseguró haber recuperado cuerpos humanos bajo las columnas (Jiménez, 2008). Conociendo Sancti Petri se comprende que Manuel de Falla se inspirara allí para su obra inconclusa para coro Atlántida.

Según las referencias de Francisco Salazar, la piedra Rompetimones (para cuya localización exacta adquirimos el Plano de Santipetri del capitán de fragata Montojo de 1872), estaba pasados los farallones al pie de la isla y, con la marea llenando, era muy peligrosa para los barcos, que procedentes de la almadraba se dirigían hacia el caño y por lo que fue volada con dinamita (Figura 3.3). Cerca de la ubicación del Rompetimones en una zona que queda descubierta con la bajamar, él vio dos piscinas con escaleras excavadas en la roca una de las cuales aún conservaba mosaico.
Ahora se había ido rellenando de arena al hacer el espigón de la punta de Las Piedras, que hace dar un giro al agua al entrar en el caño con la marea llenando. En la barra en la que los barcos areneros faenaban, refiriéndose al Placer de la Punta del Boquerón, han aparecido hasta monedas de oro que se quedan los ingenieros. El interés arqueológico de ese placer de arena se confirmó cuando a principios de la década de 1980 varias figurillas de bronce fenicias, datadas en el siglo VII a.C., y por lo tanto relacionadas con el Templo, fueron extraídas en distintas ocasiones por los barcos areneros que faenaban allí, algunas de las cuales ingresaron en el Museo Provincial (Blanco, 1985). Una de ellas, de estilo egiptizante (valorada en 80.000 pts.) que actualmente se halla expuesta en el Museo de San Fernando, apareció en un saco de arena. Fue preservada por Adolfo Bosch, que la cedió para una exposición organizada por el Ayuntamiento de Puerto Real (Bosch, inédito). Cuando el Ayuntamiento de San Fernando tramitaba la adquisición 
de la colección heredada de su abuelo (Gálvez et al., 1991) para que formara parte de la del Museo Municipal (Sáez, 2017), ésta fue incautada por la Junta de Andalucía a pesar de que el caso había sido previamente sobreseído (E.M., 1993) y. A día de hoy su dueño sigue apelando a la justicia por irregularidades en el proceso jurídico llevado a cabo para desposeerle. En 1990 a consecuencia de la aparición de las figurillas se prohibió el trabajo de los barcos areneros en ese lugar. Otro hecho que parece incomprensible, si no fuera por razones explícitas, es que en 1993 se aprobó y dotó, por parte de la Administración Autónoma, un proyecto de prospección para localizar el yacimiento de los bronces a más de $2 \mathrm{~km}$ de la punta del Boquerón, en la confluencia del caño Carbonero y el de Sancti Petri, con un barco dedicado a dragados y por indicación expresa de los propios areneros del lugar donde supuestamente habían aparecido las figurillas (Gallardo et al., 1994).

El mismo 1975 retomamos la localización de la vía donde lo dejamos el año anterior, pues según Adolfo Bosch, él había visto restos aún más hacia el sur. Volvimos a rastrear la playa de La Albufera. La marea estaba más baja que aquel momento, esta vez los restos de la vía estaban en seco, seguían por la misma playa. Localizamos testigos hasta la punta Campanilla, a la altura de la pista de tierra que entra en la playa. Es decir, que pese al fango que los ocultaba no nos habíamos equivocado al identificarlos la vez anterior (Figura 3.3). Alcanzamos casi hasta el mismo caño de Sancti Petri, reseñamos únicamente unos mojones modernos en la playa, marcas relativas al campo de tiro, según el capitán Sáez del Polígono González Hontoria, pero que, en algún caso, aprovechaban un fragmento de muro de la calzada como mojón. Por ello, nos propusimos prospectar desde el Arrecife buceando para, en sentido inverso, llegar hasta el punto supuesto donde éste se encontrara con la Vía, con objeto de mantener o desechar la hipótesis de que el Arrecife fuera el último tramo de la calzada romana. Así, una pareja se sumergió al norte de la punta del Arrecife con este objetivo, comprobando que se hundía lentamente. El agua no estaba clara, por lo que no se apreciaba del todo bien, pero se pudo asegurar que tenía aspecto de arrecife natural. Se observaron grandes bloques irregulares de roca, cubiertos de concreciones marinas y algas, que iban disminuyendo de tamaño y al finalizar la inmersión eran ya de $1 \mathrm{~m}$ de lado pero igualmente irregulares. No se hallaron restos de fábrica de mampostería semejantes a los parapetos de la Vía Hercúlea.

El día 18 de septiembre de 1975, volvimos a Sancti Petri, el patrón, Manuel Marchena, salió con el barco desde La Caleta. Primero hicimos un reconocimiento del islote y el fuerte, que estaba parcialmente derrumbado por el sudeste (Figura 5). Entre las ruinas del castillo había otras ruinas de muros, que no pude identificar por estar cubiertas de concreciones y algas, entre ellas, algunos sillares moldurados. Esa parte de la isla precisaba una excavación arqueológica de campo específica, al margen de nuestros proyectos, que arrojaría interesantes conclusiones en un lugar tan enigmático para la investigación sobre el templo de Hércules. Una intervención que permanece inédita, pero que figura en el Expediente de Catalogación de la Zona Arqueológica de Sancti Petri, se limitó a la realización de un sondeo en la parte de derrumbes del sur del castillo. La estratigrafía reflejó la ocupación del islote entre el siglo VII a.C, a partir de un tipo de puntas, "macalón" (de finales de la Edad del Bronce a principios del Hierro I), y época "tardoantigua", a partir del hallazgo de restos de una tumba (Bernal et al., 2003).

Cerca de las ruinas, ya en el agua, se apreciaba un canal excavado en la roca y hoyas circulares de diversos tamaños, la mayoría de unos $80 \mathrm{~cm}$ de diámetro, semejantes a las que aparecen en torno al castillo de San Sebastián y en otros arrecifes. No solo horadaban la roca cangrejera, sino también un estrato inferior de conglomerados de gravas compactadas, por lo cual no puede considerarse que fueran producto de la erosión por la diferencia de dureza de los estratos. En una exploración realizada en 1958 junto al Farallón Grande, los tenientes coroneles de Infantería de Marina, Gavira y Navarro, llamaron la atención sobre unos agujeros de unos 3 m de diámetro que al principio me parecieron naturales hechos por la erosión, pero.... sus paredes eran muy lisas...sus fondos medían cuatro o cinco metros de profundidad... dada la proximidad de ellos, se deducía por todo que estaban hechos de intento (García y Bellido, 1964b). Hay que recordar la existencia en las riberas de pozos, charcas o pozas de marea, cuya función ancestral es la de pescar peces, crustáceos y moluscos atrapados en ellos con la bajamar. Así mismo, cuando se registran alrededor de las fortificaciones costeras modernas, pueden responder al sistema defensivo de los propios fuertes, empalizadas y estacadas, cuyo origen hay que buscar en el propio de la fortifica- 
ción, muy extendido desde época romana hasta la Edad Moderna. La diferencia en las dimensiones de las hoyas de las estacas se deberá a que naturalmente las fuerzas de la dinámica marina las erosiona, aumentándolas y deformándolas. Como no podía ser de otra manera, buscamos el rastro de la existencia de la mítica fuente de agua dulce, que recoge Estrabón de Polýbios, que sube y baja a la inversa de las mareas (García y Bellido, 1945), sobre este tipo de fuentes o pozos que en la Edad Moderna un autor gaditano, que conocería bien el lugar, aseguraba que en Cádiz había muchos de la misma naturaleza (Suarez, 1610). En el interior de la fortificación, había dos brocales de mármol blanco de la Edad Moderna. Uno de ellos portaba una inscripción incisa en la moldura de la base (Figura 5).

\section{[.]O DE [.]Z[.. $]$ \\ SI(EN) 'DO' GOVERN(ADO) 'R', D(0)'N' ANTONIO `DE’ ACVI.E}

Aparte de otras consideraciones de mayor gravedad, se perdió una ocasión preciosa para hacer un buen estudio arqueológico con motivo de la rehabilitación del Castillo (declarado BIC) que realizó el Ministerio de Medio Ambiente de 2007 a 2010, según el proyecto de José Antonio Martín Caro, bajo la dirección del jefe de servicios de Costas, Gregorio Gómez Pina y el control arqueológico de Ana Troya (Ingenieros Consultores, 2010). Aparte de la rehabilitación del fuerte, se localizó un pozo en el patio salobre, que figura como de origen romano, se construyó una escollera de protección del fuerte, un horrible embarcadero de 27 x $6 \mathrm{~m}$ y un camino de acceso al castillo, ambos de hormigón. Testigos presenciales, alarmados por lo que presenciaban durante las obras, divulgaron a través de internet que se habrían destruido restos arqueológicos, presentando como prueba imágenes fotográficas de una máquina retroexcavadora en el momento que afectaba a las ruinas de sillería del sureste del fuerte, referidas arriba, y otras de sillares moldurados que quedaron sepultados asomando bajo la escollera, algunos de los cuales, según comentan, se utilizaron para reconstruir el camino de entrada a la rampa de entrada al fuerte (Rodríguez et al., 2010).

$\mathrm{Al}$ año siguiente, en 1976, después de obtener las autorizaciones pertinentes del Ministerio de Educación y Ciencia y de Marina, y habiendo sido concedida una subvención de 30.000 pts., reali-
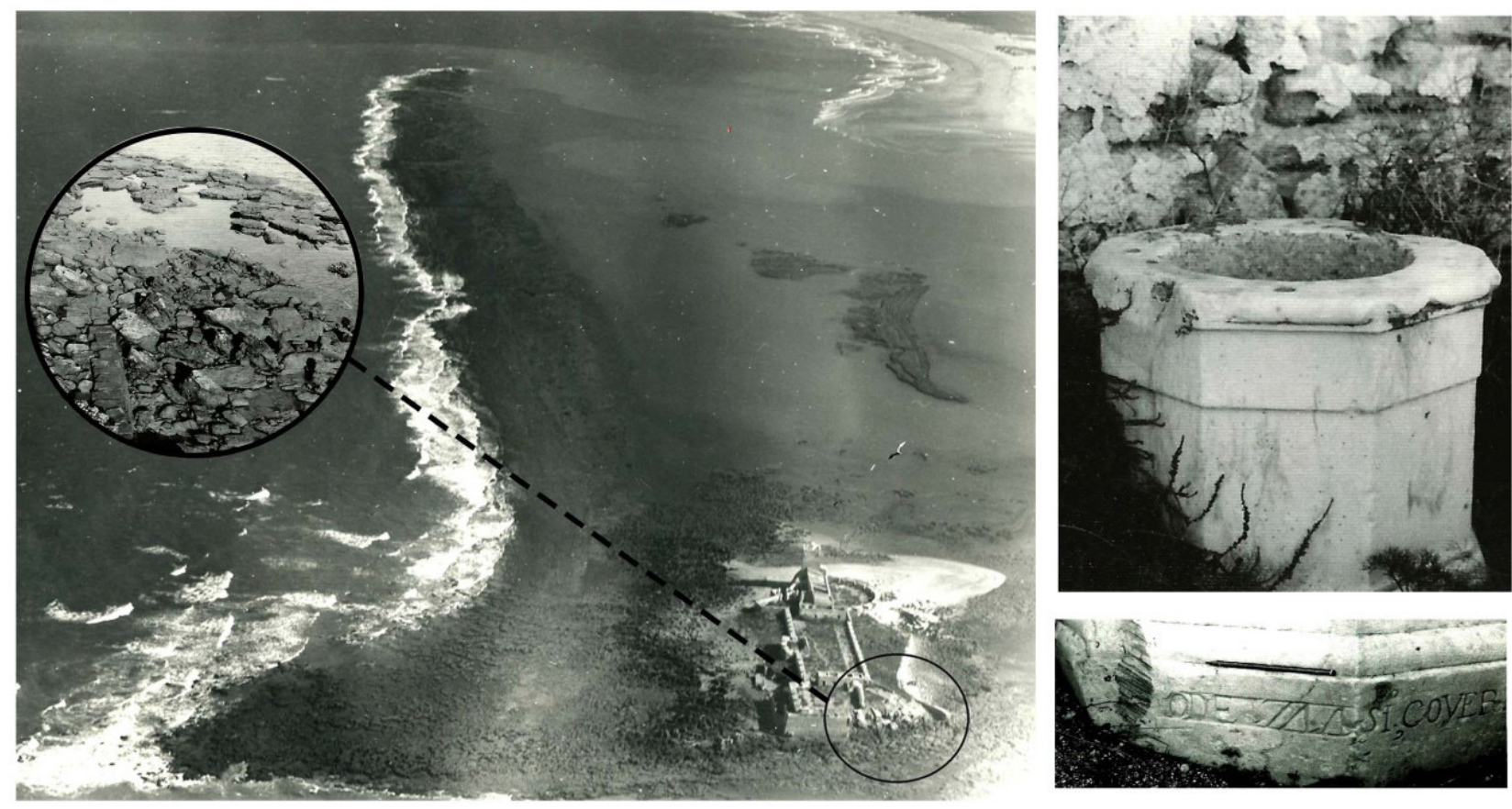

Figura 5. Izquierda: Islote de Sancti Petri, los bajos Moguerano y La Redonda y ruinas del SE del Castillo de Sancti Petri, 1973. (Fuente: Flotilla de Aeronaves de Rota, 1977). Derecha: Brocal del Castillo de Sancti Petri y detalle de la inscripción. 
zamos una corta campaña de prospección con el mismo objetivo general que hasta el momento, la Carta Arqueológica Submarina de Cádiz, solamente pudimos dedicar a San Fernando un par de jornadas. Un temporal fuerte del sur con chubascos nos impedía bucear ese día pero como se daba uno de los coeficientes más altos de marea del año, aprovechamos para volver sobre la calzada romana a prospectar la playa de Camposoto hacia Retamar. Iniciamos el recorrido en el mismo coche por la playa, donde lo habíamos dejado el año anterior, y, aunque debido al ciclón la marea no llegó a ser tan baja como era de esperar, localizamos varios testigos de la calzada en la parte descubierta, frente al Bunker I, según la actual denominación (Figura. 3). Apenas un par de muros de mampostería desplomados de la calzada fueron los últimos testigos y los más próximos al islote de Sancti Petri de todos los que habíamos registrado hasta el momento, los cuales ponían de manifiesto que, una vez cruzado el Caño, el trazado de la Vía Hercúlea discurría por la playa hacia Torregorda, donde, según la hipótesis clásica, se uniría con la Vía Augústea procedente del puente al Zuazo. Este hallazgo tan próximo y en paralelo a la punta del Arrecife, junto a los resultados de las inmersiones en la propia Punta, nos permitió concluir que la calzada no enlazaba con el islote. Era evidente que el Arrecife de la isla de Sancti Petri, en contra de lo que en ocasiones todavía se acepta, no puede ser considerado una calzada.

\section{El Pecio del Cobre}

En la campaña de 1977 manteníamos los colaboradores iniciales. Por motivos de seguridad y eficiencia seguíamos la misma norma de realizar las inmersiones por parejas, exceptuando las inmersiones individuales a remolque de la embarcación o en circunstancias especiales. Normalmente cada pareja estaba formada por los mismos buceadores, con la ventaja de que así era más fácil la comunicación debajo del agua, los errores disminuían y se ganaba en eficacia. Cada buceador se había ido haciendo a rastrear el fondo, porque al principio toda piedra con un aspecto raro, enmascarado por las concreciones, era inspeccionada detenidamente, la precisión en las descripciones había mejorado. Los recorridos arrastrados por la embarcación, con o sin timón submarino, permitían un buen reconocimiento del fondo, excepto con poca visibilidad. El problema más grave lo representaba la asistencia diaria, que era muy irregular y reducía las posibilidades del proyecto.

La campaña se realizó entre el 1 y el 15 de septiembre de 1977, habiendo desaparecido el Patronato, con las debidas autorizaciones directas de la Marina de Guerra y el Ministerio de Educación y Ciencia, que concedió una subvención de 75.000 pts. En Sancti Petri contamos ocasionalmente con los servicios de Manuel de Barbate (1.000 pts. por jornada), que pescaba por la noche al palangre con una pequeña embarcación, "Lino". El 6 de septiembre nos pasó a la isla con Levante fuerte, hicimos un recorrido muy malo, con la marea subiendo y sin botellas, desde el interior del Caño hacia la punta del Boquerón, para localizar el Rompetimones, entre $3-1 \mathrm{~m}$ de profundidad, hallamos un decepcionante fondo de arena y cascajo, estéril arqueológicamente hablando (Figura 3), al igual que en nuestras exploraciones precedentes y las realizadas en la década de los 60 del siglo pasado (García y Bellido, 1964a, 1964b). Posteriormente, con levante flojo, realizamos otros recorridos desde el muelle de Sancti Petri hasta la zona del Rompetimones, arrastrados por la embarcación con el timón de profundidad, que resultaron muy incómodos porque la embarcación, a causa de la escasa velocidad, gobernaba mal, pero a mayor velocidad era imposible ver nada por la falta de visibilidad y el fondo de arena. Registramos cerámica muy fragmentada y rodada, restos de ánforas romanas entre ellos, de los cuales levamos e inventariamos cuatro fragmentos como muestra. También hicimos recorridos desde Los Morenatos hasta la orilla contraria del muelle de Sancti Petri. La corriente era muy fuerte, revolcaba al buceador dificultando el rastreo del fondo, que observó que había muchos restos de todas épocas, pues la corriente arrastra todo lo que encuentra a su paso en esa zona, entre ellos planchas de metal que quedaban hincadas oblicuamente en el fondo. Para aprovechar decidimos a continuación prospectar en tierra, en Retamar, donde se asientan tres baterías de defensa, Urrutia, San Genís y Aspiroz, y posibles pozos de agua dulce. Nos salió al encuentro a lomos de un burro el guarda, Pablo el "Tórtola", que había nacido y todavía vivía en el mismo fuerte Urrutia, nos demostró que no había tal camino de ánforas, del que habíamos obtenido referencias orales. En el fuerte había un pozo, que según nuestro guía, había sido de agua dulce pero se había vuelto salobre. Nos enseñó otros dos pozos, uno de ellos hacia el oeste, también salobre, presentaba dos fases 
de construcción: un brocal poco elevado del suelo con un abrevadero adosado, de cemento, ladrillo y mortero de cal, de $1,40 \mathrm{~cm}$ de diámetro. Por el interior, se podía observar que continuaba $-30 \mathrm{~cm}$ por debajo del nivel del terreno, a partir del cual cambiaba su estructura con unas características interesantes. Sólo pudimos observar hasta el nivel del agua, que se iba estrechando y adoptaba forma oval y una fábrica distinta, consistente en cantos rodados del lugar de mediano tamaño, aparejados en seco. Muy próximo a la batería, el tercer pozo, de construcción similar a la misma, estaba enfoscado con mortero de cal (Figura 3).

El día que cerrábamos la campaña, el 14 de septiembre de 1977, solamente asistieron Adolfo Bosch y Gabriel Mourente, además el patrón, Manuel, se había ido a pescar pulpo al Arrecife. El encargado de los yates del club Náutico nos hizo el servicio por 300 pts. En primer lugar iniciamos un recorrido de un solo buceador desde los Farallones hacia el Rompetimones, pero al comprobar la imposibilidad de obtener resultados, porque, para variar, estaba muy turbia el agua y hacía mucho levante, decidimos ir a realizar la prospección a sotavento del castillo. Allí nos tiramos los tres a la vez cuando empezaba a subir la marea. A 20 metros de iniciar el recorrido, en un fondo de arena y piedra a $7 \mathrm{~m}$ de profundidad con $40-60 \mathrm{~cm}$ de visibilidad, descubrimos semienterradas unas 10 "tortas" de cobre, de color verde que ocupaban un área de unos $20 \mathrm{~m}^{2}$ (Figura 6). Creímos ver un ancla cerca, pero en realidad eran dos piezas grises, de 35 y $70 \mathrm{~cm}$, que formaban un ángulo. Una de ellas, después de inspeccionarla bien, resultó ser un lingote de plomo alargado y la otra, una laja de piedra o plancha de un material sin identificar. La falta de visibilidad no permitía tener una visión general del conjunto, por lo que hice varios croquis. Después de situarlos radialmente con brújula, levamos a bordo dos de los lingotes de cobre más pequeños, como muestra. A unos $60 \mathrm{~m}$ del pecio localizamos un ancla de piedra grande, de 60 $\mathrm{cm}$. de diámetro, tipo flotador, y otra de alrededor de 1,30 m de longitud, posiblemente de hierro, de las que anclaban las redes de la almadraba. Debido a que los galápagos de cobre de un color verde intenso por el cardenillo fueron los primeros que descubrimos e impresionaron nuestras retinas, denominamos el yacimiento "Pecio del Cobre" (Vallespín, 1986a).

Habíamos alcanzado buena parte del objetivo propuesto para la elaboración de la Carta Arqueo- lógica Submarina de Cádiz, que sirviera de base a futuras excavaciones como el elemento más eficaz para el conocimiento del rico patrimonio arqueológico sumergido y su defensa de las agresiones producidas por los agentes ambientales y el expolio que sufría. Se imponía ya el interés científico de excavar un barco hundido, una "cápsula del tiempo", cuyo estudio siempre aporta una considerable cantidad de datos en poco tiempo. Los medios con que contábamos y la precariedad de las subvenciones solamente nos habían permitido, y con dificultades, realizar prospecciones visuales sin ningún tipo de medios técnicos. Sin embargo, en 1978 consideramos, que el Pecio del Cobre era uno de los yacimientos más importantes de entre los que hasta ese momento habíamos registrado y que se imponía emprender la excavación sin dilación a pesar de las dificultades, porque debido a su accesibilidad y al propio valor de los metales en el mercado se hallaba en grave peligro de expolio, acrecentado al haberse difundido por la prensa el hallazgo. La subvención era algo mayor que la de años anteriores, ascendía a 400.000 pts., por el interés personal mostrado por Maluquer de Motes, nuevo Comisario General de Excavaciones, para que emprendiéramos su excavación.

Se incorporaron al grupo algunos nuevos colaboradores, buceadores con sus propios equipos, Jaime Gómez, Pedro Valverde, Carlos Calvo, Enrique Ferragut, José Manuel Carreño, José Manuel Rodríguez, Pedro María González Quevedo, Vicente Herranz, José María Moral, Eduardo Prats Loaisa, José Ángel Andrés Lobato como fotógrafo submarino, Guillermo Parrilla, dibujante, y un voluntario de superficie, Antonio López Carrasco. Recibimos la colaboración de la Unidad de Operaciones Especiales (UOE) del Tercio Armada con personal, equipos de buceo y embarcaciones (Vallespín, 1986), así como miembros del Club Náutico de Sancti Petri, Marín, Presidente, Juan Bernal y el Secretario, Manuel Valverde. Contamos por primera vez con un compresor para llenar las botellas, una "chupona" experimental, que accionábamos con botellas de aire comprimido a falta de compresor; 5 embarcaciones, 2 neumáticas, una de 8 plazas y motor de $32 \mathrm{cv}$, otra, de 6 plazas y motor $32 \mathrm{cv}$, y otras 3 de fibra, la "Pabla" de $7 \mathrm{~m}$ de eslora, $2 \mathrm{~m}$ de manga y motor volvo de $60 \mathrm{cv}$, prestada por Juan Bernal, comodoro del Club Marítimo y tripulada por Francisco Cifuentes (Figura 7), la Fanny, de $5 \mathrm{~m}$ de eslora y motor $15 \mathrm{cv}$., prestada por Manuel Valverde, y una patera, prestada por 

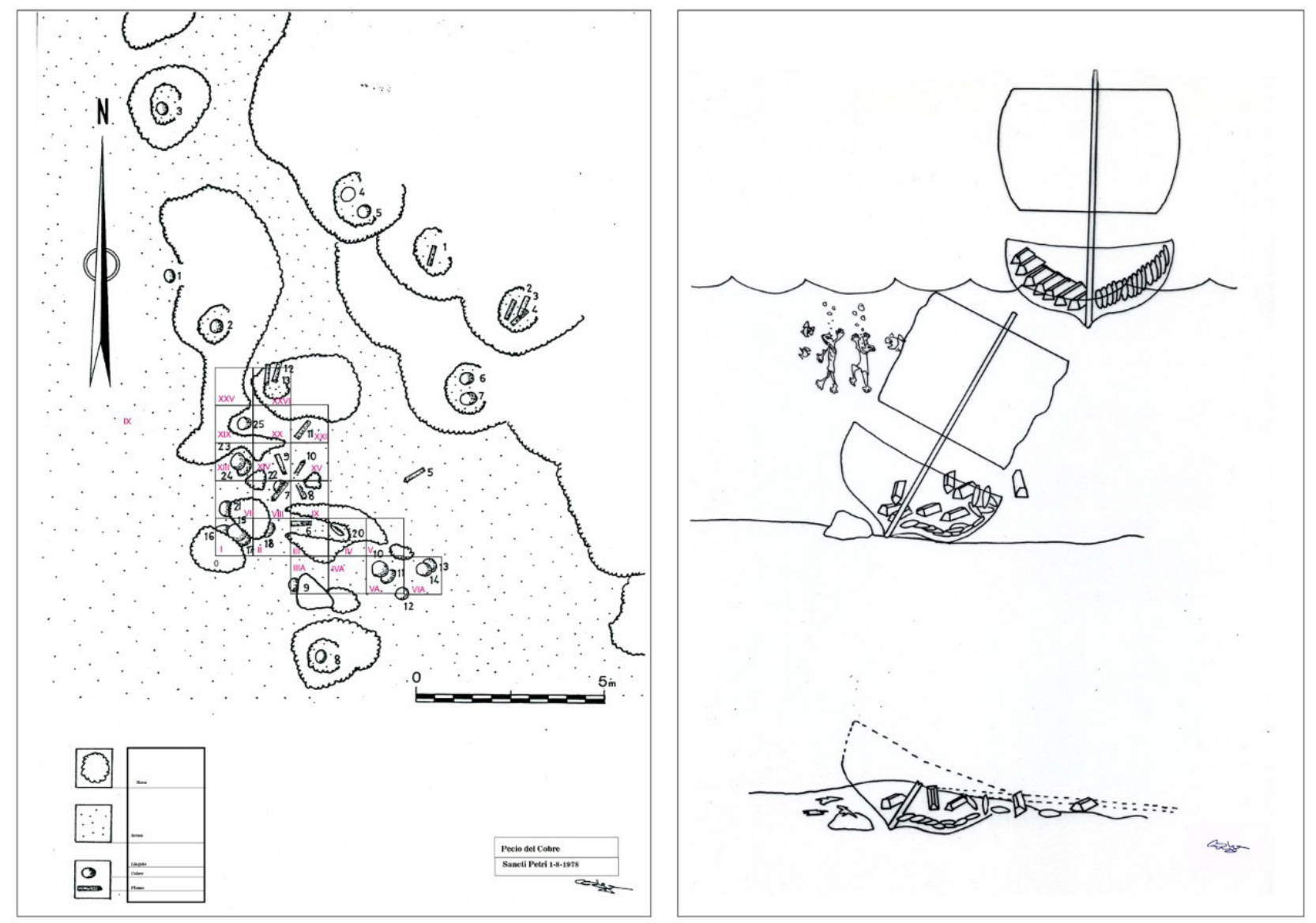

Figura 6. Pecio del Cobre: plano e interpretación del naufragio.

Paulino Bueno. Fue decisivo para mejorar la marcha de la excavación, el que, a través de César Lazaga, se nos permitiera disponer de una base en el poblado almadrabero, una vivienda con agua potable, la fábrica de atún, que disponía de corriente eléctrica para el material de buceo y el compresor, y un pequeño almacén con dos estancias a pie de playa para el material arqueológico.

Iniciamos la primera campaña de excavación submarina el día 1 de agosto y cerramos el 12 de septiembre de 1978. Las primeras inmersiones no nos permitieron tener una visión general del pecio ni hacer fotografías con un mínimo de calidad, debido a lo turbia que estaba el agua. Para concluir la primera fase de documentación sin esperar a que se aclarara el agua realizamos un croquis del pecio, según el método radial para situar los materiales. Registramos los lingotes a la distancia exacta y con la orientación correcta respecto al punto cero, mediante un cabo amarrado al mismo, debidamente marcado cada $1 \mathrm{~m}$ o cada $2 \mathrm{~m}$ de con la ayuda de la brújula y girando en torno a él. A través de los croquis destacaba un punto más fér- til al sur del conjunto que elegimos para instalar la cuadrícula (Figura 6). Para facilitar lo más posible el trabajo en el fondo, montamos en superficie cuadrículas pequeñas con varillas de hierro $1 \mathrm{~m} \mathrm{x}$ $1 \mathrm{~m}$ de lado y $6 \mathrm{~mm}$ de grosor, soldadas y pintadas de minio de color naranja, que además de hacerlas más llamativas, las protegería de la corrosión marina. El método de fijación fue también el más sencillo que pudimos encontrar, lastrar con muertos y amarrar las cuadrículas entre sí, procurando su nivelación y siguiendo un eje de coordenadas $\mathrm{N}-\mathrm{S}$ y E-W, cuyo centro es el punto $\mathrm{O}$. Hacia el norte de la cuadrícula 1 en adelante se alcanzaron $5 \mathrm{~m}$, hacia el este $6 \mathrm{~m}$, hacia el sur $1 \mathrm{~m}$. Después de los trabajos iniciales pudimos delimitar el pecio compuesto por lingotes de cobre de planta circular y troncopiramidales de plomo de base rectangular alargada. Ocupaban un área de $27 / 20 \mathrm{~m}$, sobre un fondo de arena y rocas del límite oeste sumergido del Arrecife, a una profundidad de entre 6 y 9 (6 m con marea escorada). El primer día que hubo un poco de visibilidad para ver el pecio con un poco de perspectiva ya habíamos levado los lingotes del 

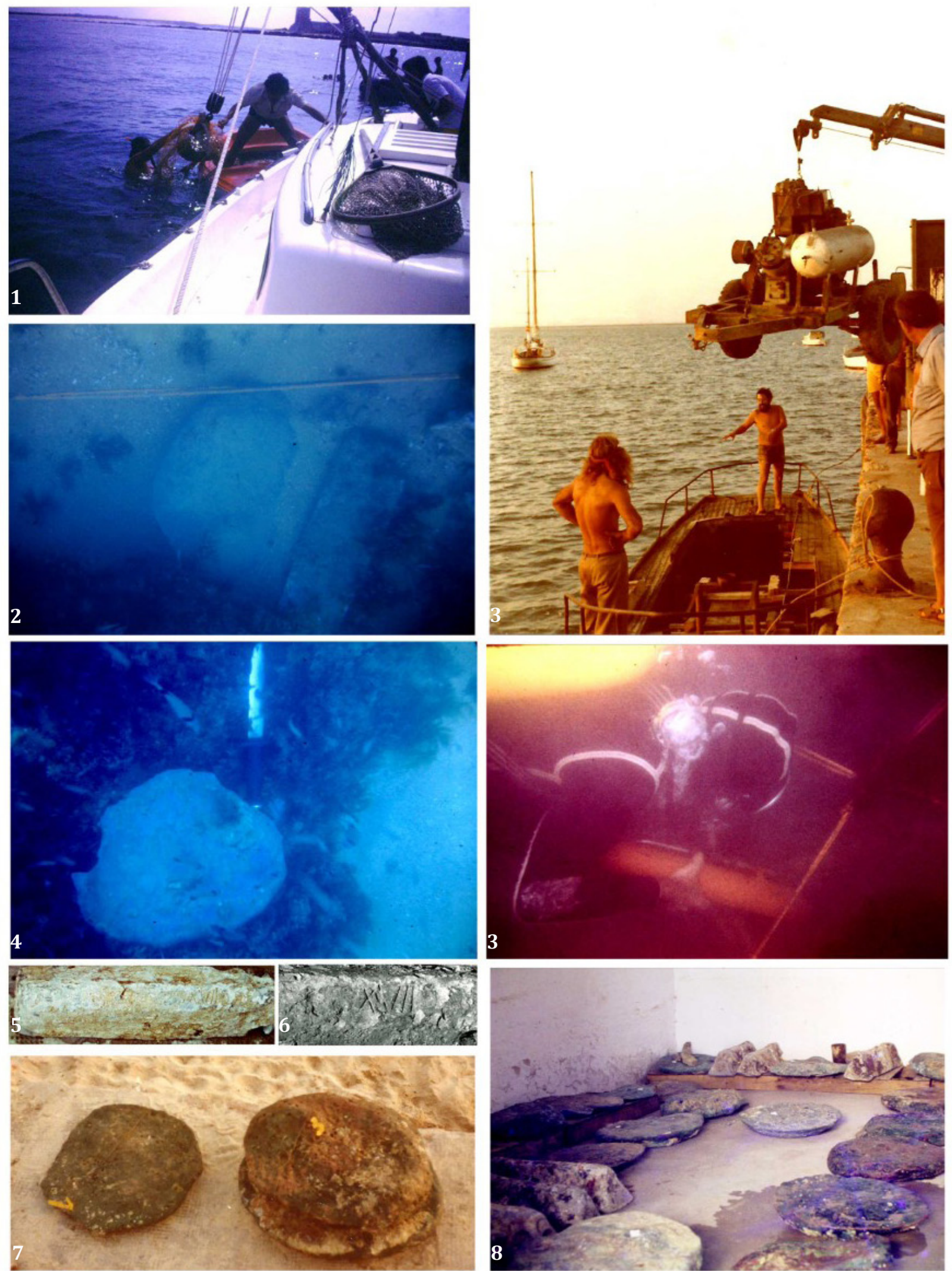

Figura 7. Pecio del Cobre. 1. Excavación desde la "Pabla" (1978). 2. Lingote de cobre in situ № 8. (Fuente: Lobato). 3. Instalación del compresor para la manga de succión en el "Río Iro", 1979. 4-5-6. Cuadrícula VIII, lingote de cobre № 22 y de plomo № 7. (Fuente: Lobato) 7. Lingotes de cobre desembarcados en el muelle del poblado de Sancti Petri. 8. Lingotes en el almacén de la almadraba. (Fuente: O. Vallespín). 
exterior de la cuadrícula, que aunque estaban más aislados unos de otros (Figura 6), no estaban muy disgregados, a veces aparecían en grupos de dos o tres, tal como quedó reflejado en el plano. Después de situarlos numeramos los lingotes con cifras recortadas en plástico de colores antes de levarlos a bordo de la embarcación por medio de una red y una polea instalada en la misma. Aparentemente, sobre todo en la zona cuadriculada, los lingotes conservaban la posición que tomaron al caer en el momento del naufragio, unos clavados de canto, otros de plano y otros, incluso, apilados unos encima de otros, en alguna ocasión con grandes rocas sobre ellos, en huecos de las mismas o parcialmente cubiertos de arena (Figura 6 y 7). Al oeste de la cuadrícula se extendía una zona arenosa en la cual no había ni un solo lingote a la vista, sin embargo en las otras direcciones de los galápagos se intercalaban con la arena y las piedras del roquedal del pie del Arrecife.

Los lingotes de cobre eran redondeados, planoconvexos (Figura 7). Todos respondían al mismo tipo pero no se registró un lingote igual a otro. Había gran diferencia de peso entre el mayor $(84 \mathrm{~kg})$ y el menor (13 kg), en general el peso medio de los lingotes superaba al característico de los lingotes españoles que estaba en esos momentos entre los 20 y los $30 \mathrm{~kg}$. (Domergue, 1966). A este tipo de menor peso corresponden los lingotes recuperados en los dragados realizados en 1992 con motivo de la regeneración de la playa de Regla (Rico et al., 2010) y algunos lingotes extraídos con las autorizaciones pertinentes por la compañía chatarrera Flozaga en el Bajo del Picacho de Chipiona, donde se documentaron dos denarios aúreos de entre los años 64-69 d. C. (Vallespín, 1985). Según consta en el escrito firmado por el propietario de la concesión, Adolfo Bosch consiguió salvar algún ejemplar, "evitando que se perdiera" junto al resto de los lingotes extraídos, que fueron vendidos al peso para fundición durante los años que duró la concesión $(1.558 \mathrm{~kg}$ de cobre y $4.827 \mathrm{~kg}$ de plomo, según escrito de la Ayudantía de Marina de San Lucar de Barrameda de 14-8-1976). Las diferencias formales entre los lingotes del Pecio del Cobre, se pueden explicar porque el molde sería el propio crisol del horno o un simple hoyo en la tierra. El perímetro y el diámetro es muy similar en todos los galápagos recuperados del Pecio del Cobre, las desiguladades estriban en el peso, el borde de la cara superior y la sección. Algunos poseían una orla lisa alrededor que se debe al hecho de que la poca cantidad de metal del borde se enfría más rápidamente que el resto y no da tiempo a que se libere el gas y presente el aspecto burbujeante de la parte central. Es corriente que aparezcan inscripciones en esa zona en lingotes de este tipo, pero en ninguno de éstos se apreció su existencia.

Los lingotes de plomo tenían forma de tronco de pirámide alargada, la base de dimensiones muy regulares de $51,30 \mathrm{~cm}$ y $55,00 \mathrm{~cm}$, la altura oscilaba entre 11,30 y los $15,00 \mathrm{~cm}, \mathrm{y}$ un peso medio de $60,20 \mathrm{~kg}$. Tenían el dorso redondeado en los extremos y plano en el centro, donde se alojaba una cartela de dimensiones idénticas en todos $(25 \times 3$ $\mathrm{cm}$ ). Algunos estaban muy erosionados y parcialmente cubiertos de concreciones marinas, que a veces tapaban la cartela impidiendo comprobar si existía inscripción. Solo un lingote (№ 11) de color gris, más oscuro por la parte que había estado enterrada, y tacto pulverulento, portaba inscripción incisa en la cartela. La cartela ocupaba un espacio bien centrado en el dorso, su extremo derecho alojaba los siguientes caracteres latinos realizados con un estilete puntiagudo (Figura 7): XVII.

Los trazos, muy claros, respondían a una escritura natural realizada a mano alzada. Resulta muy extraño que la inscripción fuera incisa en la cartela, pues en las cartelas se debe alojar el sello, cuya matriz en negativo deja en relieve las letras. Interpretamos la inscripción como un numeral o el final del mismo, realizado en frio una vez extraído el lingote del molde, al que no se le habría puesto sello intencionadamente. Si se tratara del final de una cifra, tal vez podría corresponder al peso del lingote en libras, pero ese tipo de incisiones epigráficas suelen aparecer en los laterales de la pieza. Los numerales en el dorso son raros, aunque algunos lingotes británicos los presentan. Al igual que la mayoría de los ejemplares de plomo, tenía un orificio de sección cuadrada de $3 \times 3 \mathrm{~cm}$ de lado y $9 \mathrm{~cm}$ de profundidad en su base. En el momento del estudio no encontramos paralelos a esos huecos. En algunos lingotes se han registrado marcas de garfios para su manipulación (Tylecote, 1962) y uno rectangular iba provisto de unos tetones para su manejo en el transporte (Bouscaras, 1964). Parece que esos huecos rectangulares profundos se deben a una barra para sacarlos del molde, puesto que evidentemente se realizaron en caliente. Han surgido paralelos en los cuatro lingotes de plomo del mismo tipo recuperados en el mencionado dragado de Chipiona y en la excavación del pecio Bou Ferrer, un barco con un cargamento de ánfo- 
ras Dr. 7/11, cuyo puerto de origen sería Cádiz, en el que se han registrado cuatro lingotes de plomo, muy similares por su forma, dimensiones y peso con letreros impresos AVG.CER. Estos últimos se pueden considerar algo más evolucionados que los nuestros, por su sección triangular y mayor longitud (3-5 cm.) Ahora bien, ambos presentan las mismas perforaciones, rectangulares, que emparentan fielmente los modos de producción en la fundición de ambos cargamentos, aunque los autores de la publicación aseguran erróneamente que se trata de la primera vez que se documentan (Juan et al., 2012; Rico et al., 2010).

Cerramos la campaña afianzando las cuadrículas y los muertos en el fondo, después de haber embarcado en la patera los últimos 10 lingotes que teníamos a la vista para evitar saqueos, quedando ocultas bajo la arena dos tortas de cobre en la cuadrícula I, donde habíamos realizado previamente un sondeo con la chupona (Figura 7). De vuelta, remolcamos la patera como siempre, pero al rebasar la punta de Las Piedras el rebullir del rompeolas hundió la patera en medio del Caño. Volvimos a recuperarla esa misma tarde, pero la fuerte corriente y el peso de los lingotes, nos impedía reflotarla y remolcarla, porque solamente éramos dos en inmersión, Adolfo Bosch y yo misma, y, el patrón, Manuel Valverde, en superficie. Fuimos aliviando el peso de la patera a base de extraer lingotes y depositándolos al lado. Cuando solamente quedaba un lingote en su interior, la patera fue arrastrada con fuerza por la corriente hasta fuera de la punta de las Piedras (Figura 3). Recuperamos la patera y el lingote, pero la localización de los otros 9 lingotes, nos obligó a realizar numerosos rastreos cada vez más amplios, barriendo el fondo durante toda una semana. Aparte de buscar los lingotes, los rastreos nos sirvieron para constatar la presencia de materiales de diversas cronologías arrastrados por las fuertes corrientes, entre ellos fragmentos de cerámica de varios tipos, pero siempre aislados y muy rodados. También localizamos restos de construcción en la margen derecha del Caño, cuyo examen no pudimos realizar con el detenimiento preciso (Figura 3). Hay que reseñar que en 1992, al año siguiente del dragado realizado para remodelar el nuevo Puerto Deportivo, se realizaron prospecciones y el control arqueológico de la extracción de arenas en la punta del Boquerón para reponer la playa de La Barrosa. De los vertidos de la draga en la propia playa, se recuperaron 300 fragmentos de cerámica, de los que seleccio- naron 85, ánforas de salazón de fabricación local, tipo Dressel 7/11 C, Mañá C2b, y Keay IV y XL, así como cerámica común y fina romana del siglo del I-IV d.C., a lo que hay que añadir, jarros y cántaros medievales hispanomusulmanes, datados en el siglo XI-XII. En 1993 fueron descubiertos casualmente cerca de allí en el centro del Caño, la denominada "Zona C" o, posteriormente, "Lavaculos", distribuidos irregularmente por el fondo diversos materiales arqueológicos de idéntica tipología y cronología. Identificado el pecio como acumulación de materiales, fondeadero e, incluso, como varios naufragios, se extrajeron más de 365 piezas de cerámicas, romanas y medievales, fechadas entre el siglo I-V d.C., e hispanomusulmanas, entre el XI-XII (Ruíz et al., 2002) (Figura 3).

Hay que tener en cuenta la profunda alteración medioambiental constatada como consecuencia de la remodelación del puerto deportivo de Sancti Petri. La incidencia fue patente, produjo un cambio en la dinámica de arrasamiento, acarreo y deposición, tanto hacia mar abierto como hacia la Bahía. Las arenas y fangos en algunos puntos fueron acarreados y depositados en otros. En tanto la margen izquierda iba siendo arrasada a gran velocidad, en la punta del Boquerón y en el fondo del Caño se produjo la acumulación de gran cantidad de arena y depósitos, entre ellos materiales arqueológicos. Algunos pecios fueron quedando a la vista a partir del 1991, siendo descarnados y arrastrados restos arqueológicos de diferentes tipos, entre ellos restos de construcción en Las Hermosillas y naufragios completos. Como los restos de madera de un barco con cerámicas hispanomusulmanas, visible en el corte del talud bajo $4 \mathrm{~m}$ de sedimentos (Vallespín, 1995, 2000), del que sin lugar a dudas provienen muchos de los materiales hispanomusulmanes documentados en la referida "Zona C". De ahí que, si en las prospecciones realizadas entre 1973 y 1979 solamente se apreciaban materiales superficiales muy rodados y fragmentados, de un año para otro, literalmente de 1991 a 1992, después de las obras del club deportivo aparecieran en la punta del Boquerón y en el centro del Caño, dispersos en un gran espacio de más de $100 \mathrm{~m}$ de radio, materiales idénticos y poco rodados (Ruíz et al., 2002).

Volviendo a la excavación del Pecio del Cobre, cuando todavía quedaban algunos lingotes por inventariar y fotografiar, informé a la Directora del Museo que habíamos terminado para que viniera a verlos, pero ella se adelantó y envió un coche y 
un camión de la Diputación para recogerlos y llevarlos al Museo con sus colaboradores, entre ellos nuestro homenajeado, Antonio Sáez, junto a Paco Giles, José Antonio Ruiz Gil y Ángel Muñoz Vicente, que nos ayudaron amablemente a terminar de inventariarlos, pesarlos y medirlos. El lingote de la inscripción, que había sido uno de los rescatados el día anterior, estaba todavía en el patio de la casa endulzando, porque en el almacén no había agua, por lo que fue transportado y entregado posteriormente en el Museo por Adolfo Bosch personalmente.

La tercera campaña de excavación del Pecio del Cobre, al año siguiente, mantuvo el grupo de voluntarios, excepto Gabriel Mourente, Jaime Ruiz Coto, Antonio Muñoz Gaviño, Vicente Herranz y José María Moral. Se incorporaron, como colaboradores de superficie, José Ramón Vallespín, Ángelo y Domingo Galán, y como dibujante, Jacqueline Gobert. La Armada volvió a prestarnos su apoyo, con personal de la Unidad de Operaciones Especiales del Tercio de Armada (UOE), los capitanes Juan Pardo de Donlebún y Manuel Giles, el sargento Carmona, y el cabo 1ํㅡ Camacho, además con equipos de buceo individuales, una embarcación neumática con motor fuera borda y rezones para anclar la cuadrícula y sustituir los muertos de piedra. Adolfo Bosch puso a nuestra disposición un pequeño barco pesquero reconvertido en arenero, el Río Iro, de 11,25 m de eslora, 3,75 de manga, 1,60 de puntal, motor diésel de $64 \mathrm{cv}$ (Matrícula 40 CA-4-226), en el que instalamos un motor y un compresor industrial para la manga de succión (Figura 7), y Carlos Calvo nos cedió una embarcación con motor. Pudimos contar una vez más con la indispensable base en tierra, casa, almacén y chanca del poblado, con el permiso del Gobernador Militar de quien dependía el poblado.

Nos costó localizar el pecio debido a los fuertes temporales de ese invierno que habían cambiado notablemente el aspecto del fondo. Hallamos todas las cuadrículas amontonadas en dos grupos al pie de las rocas del Arrecife, parecía que se habían desplazado algo hacia el NE, pero no mucho porque entre ellas también estaban las palancas que utilizamos el año anterior para mover las piedras grandes de la cuadrícula I. Localizamos en superficie 6 nuevos lingotes, 5 de plomo, entre 1-4,50 $\mathrm{m}$ al SE de las cuadrículas, donde instalamos un nuevo punto 0 , y 1 de cobre, $7 \mathrm{~m}$ al SW del mismo. Realizamos diversos recorridos de rastreo por el entorno localizando un pequeño cepo de plomo partido en dos de 27,70 kg, $50 \mathrm{~m}$ al E. del punto 0 . Similares a los de la campaña anterior, los lingotes estaban cubiertos de algas y concreciones de tiempo, lo que ponía en evidencia que llevaban bastante tiempo descubiertos, es decir que no habían sido desenterrados por los fuertes temporales del invierno. El primer paso era recomponer y restituir la cuadrícula en la posición en que la habíamos instalado el año anterior. Después de diversos intentos, en los que realizamos sondeos en la arena con la chupona para localizar los lingotes subyacentes sin éxito, llegamos a la conclusión de que era imprescindible utilizar medios técnicos adecuados, como un detector de metales submarino. Todo fue en vano. Después de varios intentos de hacernos con uno no pudimos conseguirlo. No había otra solución que posponer la excavación hasta obtenerlo para poder delimitar el yacimiento. Realizamos los planos y fotografías pertinentes y levamos los 6 lingotes y el cepo. Con ellos, a lo largo de las tres campañas, sumamos en total 28 lingotes de cobre y 18 de plomo, que representaba el cargamento de un barco romano naufragado del cual no habíamos documentado resto alguno.

Hay que tener en cuenta que las condiciones de conservación eran muy negativas, por dos factores, en primer lugar la ubicación del pecio a tan poca profundidad, muy expuesto a la dinámica del oleaje, en agua templada y en fondo de arena, donde las posibilidades de preservación de los restos orgánicos son nulas, a causa de organismos marinos como el teredo navalis que devora la madera. Sin embargo sería muy posible que el resto del cargamento de metal, algo de cerámica o pertrechos metálicos se ocultaran bajo la arena, teniendo en cuenta que la eslora de una nave mercante romana puede alcanzar más de $27 \mathrm{~m}$, justo la extensión que ocupaban de norte-sur los lingotes sobre el fondo (Figura 7). Las conclusiones a las que podíamos llegar no podían ser determinantes, porque los materiales registrados hasta el momento debían constituir solamente la punta del iceberg, por tanto no se podían considerar suficientemente significativos. Con las reservas propias de estos casos atribuimos el cargamento a un barco hundido, probablemente de carga, navis oneraria, de época temprana julio-claudia, a partir de la forma de los lingotes de plomo, de tipo troncocónico de dorso redondeado, clasificados como de transición entre los republicanos, semicilíndricos, y los imperiales, de sección triangular, (Domergue, 1966). El Pecio del Cobre representó el primer hallazgo en el que 
se hallaban reunidos dos metales como cargamento de un mismo barco, cobre y plomo, cuyas minas no se dan juntas. Y en cuya explotación sobresalió la Hispania romana, famosa por la producción de metales en general y en particular de cobre, en las cuencas de los ríos Tinto y Odiel, y de plata y plomo, en Sierra Morena aparte de Cartagena. El Pecio del Cobre testimonia la importancia de Cádiz como metrópoli y del Templo de Hércules como principal puerto exportador de materias primas a Roma. Uno de los factores a considerar es precisamente el emplazamiento del naufragio, pues no se encuentra en las riberas de la ciudad de Cádiz, sino varios kilómetros al sur, junto al islote de Sancti Petri, muy próximo al templo de Hércules (García y Bellido, 1964a). El Templo se afianza como lugar de escala obligatoria para el marino de la Antigüedad. Además de su carácter puramente religioso, donde hacer sacrificios para que los dioses sean propicios, los templos costeros cumplían una decisiva función económica, política y administrativa. Eran verdaderos centros hidrográficos, que señalaban rutas, peligros, cabos, estrechos, bajos y vientos favorables. Faros que señalan el camino a navegantes y peregrinos, aduana en la que se pagan tributos. Precisamente la situación de los restos, al pie del Arrecife, debe ser interpretada como una de las causas que justifica el naufragio, pues de no tener que arribar al puerto del Templo, el barco no tendría por qué navegar tan cercar de la costa exponiéndose a los peligros que eso representa.

Fue el primer trabajo de excavación submarino científico, realizado bajo la dirección de un titulado en Historia y buceador profesional. La carencia de medios se mantuvo en los años posteriores a la tercera campaña, impidiendo continuar las excavaciones con las mínimas garantías. Era de esperar que los resultados de las siguientes campañas empezaran a arrojar luz sobre todas las incógnitas, entre ellas, la aparición de otros materiales que no fueran el propio cargamento metálico. La Dirección General del Ministerio de Cultura se puso en contacto conmigo para que preparara un artículo sobre el Pecio del Cobre para publicarlo en breve. Una vez realizado lo entregué personalmente, texto, fotografías y dibujos originales. Posteriormente, sin que hubiera salido dicha publicación, me llamaron del Ministerio para devolverme los planos y los dibujos arrugados que habían encontrado detrás de un armario, pero sin texto ni fotografías. El descubrimiento fue resumido y pu- blicado, sin mi consentimiento, ni información alguna (Blánquez, 1982). El tiempo de espera a que saliera dicha publicación del Ministerio, fue la causa de que por mi parte se retrasase la publicación (Vallespín, 1986a).

Cuarenta años después, un nuevo pecio viene a confirmar las conclusiones de la escala obligatoria en el Templo antes de iniciar la travesía. Otro cargamento de tortas de cobre, localizado en las proximidades, a alrededor de $2 \mathrm{~km}$ al norte del Pecio del Cobre. Fue descubierto casualmente por Miguel Aragón y Juan Palacios en 2011, siendo denominado Arapal en su honor, del que han sido recuperados 47 lingotes por la Universidad de Cádiz (UCA) (Cerezo, 2017).

\section{Paralización de las primeras investigaciones científicas submarinas de Cádiz}

La década de los ochenta y los primeros años de los noventa estuvo marcada por la sucesión de dragados muy negativos para la arqueología submarina en Cádiz. En 1982 el Dragado de la Canal de Entrada al puerto de Cádiz se llevó a cabo sin el debido control, ni siquiera una prospección previa. La operación consistió en el cribado en superficie de los materiales arrancados de contexto y expulsados por las bocas de las mangueras. Entre 7 y $9 \mathrm{~m}$ del nivel del fondo fueron rebajados por las dragas, revolviendo un depósito de fango y restos arqueológicos depositados durante siglos en una cama protectora de fango. De la magnitud del desastre dio una aproximación el propio director de la operación, Ramón Corzo, manifestando públicamente que solo se pudo cribar la milésima parte del material extraído del fondo del mar. Fue uno de los primeros acontecimientos que afectaron de lleno a la línea de flotación iniciada por la arqueología submarina, causando quejas en foros internacionales y un gran desprestigio de la misma entre la ciudadanía (Damián, 1986).

Las investigaciones iniciadas, en particular la Carta Arqueológica Submarina y las excavaciones del Pecio del Cobre, quedaron paralizadas a partir del año 1985 por la negativa reiterada de las nuevas autoridades competentes de la Junta de Andalucía a conceder las autorizaciones correspondientes, sin considerar el daño que el abandono iba a ocasionar al patrimonio sumergido. Con alguna excepción, todas las solicitudes de proyectos fueron denegadas desde 1985, en tanto no se trazara, "un plan general de actuación en la Bahía 
de Cádiz" (Villalobos, 1991).

A partir de 1985 se fue bosquejando un megalómano plan, el Proyecto Galeón. En principio se trataba de un barco fenicio, pero fue desechado, y con motivo de la celebración del Quinto Centenario del Descubrimiento de América se consolidó la idea de realizar una hazaña similar al Wassa o Mery Rose, localizar y recuperar un galeón de la Carrera de Indias para mostrarlo en la Exposición de 1992 de Sevilla (Amores, 1984), con la participación del Subdirector General de Arqueología y Etnografía del Ministerio de Cultura, Martín Bueno, la Comisión Nacional del Quinto Centenario (dependiente del ministerio de Hacienda), el Comité Conjunto Hispano Norteamericano, el Ministerio de Cultura y la Junta de Andalucía, bajo la dirección de Víctor Antona, entonces Director del Centro Nacional de Arqueología Submarina. El desastre de tal operación, que había alcanzado un costo de alrededor de 1.000 .000 .000 pts., se produjo muy pronto, el 2 de noviembre de 1989 el Proyecto Galeón ya había fracasado (Busquets, 1989). A día de hoy no se ha escrito ni una sola línea científica sobre el resultado, ni la justificación del gasto del inacabado proyecto. Al fracaso del Proyecto Galeón sucedió un periodo negro de acusaciones de expolio, descalificaciones personales, requisas de ánforas, cepos y otros objetos de locales públicos, denuncias falsas, prohibición de extracciones a los areneros de Sancti Petri, incautaciones de colecciones privadas, entre ellas la citada anteriormente, con imposición de una multa millonaria a uno de los más eficaces colaboradores de las únicas investigaciones científicas llevadas a cabo hasta el momento. En 1993 se reiniciaron las prospecciones submarinas. La Junta de Andalucía aprobó el proyecto, presentado como novedoso y sin precedentes, de una nueva Carta Arqueológica Subacuática de la Bahía de Cádiz, del que se excluyeron nuestras investigaciones por dos razones, según aseguraron los nuevos directores del proyecto, por falta de continuidad (después de haberlas prohibido) y haber tenido una dirección de fuera de la comunidad autónoma andaluza (Gallardo et al., 1995). Fue una derrota difícil de asumir, sobre todo al tener noticias de que en 1998 se había autorizado, sin el preceptivo control arqueológico español, a la empresa Odyssey Marine Exploration llevar a cabo el proyecto Black Swam (Cisne Negro), cuyo objeto era localizar los restos del HMS Sussex, hundido en 1694, mediante prospección con potentes medios técnicos de detección submarina. El resultado fue que en 2006, la citada empresa expolió un naufragio de un barco de bandera española, la fragata Nuestra Señora de las Mercedes, hundida frente al cabo de San Vicente en 1804 por la artillería inglesa. A través del buen hacer de los abogados españoles ante los tribunales de Tampa y Atlanta se logró la devolución de 500.000 monedas, principalmente reales de a ocho de plata, y algunos otros objetos de los saqueados durante tan largo periodo de actuación, gracias a que se tuvo en cuenta la apelación por parte española de que la fragata pertenecía a la Armada Española por lo que gozaba de inmunidad soberana (O'Donnell, 2013).

Una esperanzadora perspectiva para recuperar nuestra herencia cultural, ese enorme tesoro submarino gaditano, la representan los controles arqueológicos previos y seguimiento continuado de los dragados (Higueras- Milena, 2002), así como recientes estudios serios y su adecuada difusión (Sáez et al., 2018). Incluso es posible que se retomen las investigaciones pioneras interrumpidas. Muy recientemente, a principios de 2019, el Instituto Andaluz del Patrimonio Histórico (IAPH), se puso en contacto conmigo para requerir información sobre la localización y delimitación del Pecio del Cobre. Al enviar los datos requeridos expresé que se trata de una conveniente iniciativa y que quedaba a su disposición para cualquier detalle que fuera preciso, incluida la colaboración personal en la prospección que pudiera llevarse a cabo. Aunque teniendo en cuenta que, desde que se interrumpieron los trabajos para continuar al año siguiente han transcurrido más de 40 años, el abandono durante tan prolongado periodo de tiempo debe haber causado un deterioro irreparable en el Pecio del Cobre.

\section{Agradecimientos}

Aunque no los cite uno a uno y lamentando que algunos ya nos han dejado, quiero expresar mi agradecimiento sincero a todos los buceadores y a todos los que de una manera o de otra colaboraron en las investigaciones entre 1973 y 1985, porque sin ellos no habrían sido posibles: Francisco Salazar, Ricardo Vallespín Raurell, Matilde Gómez Martínez, Concepción Blanco, José María F. Bastarreche, Adolfo Bosch Lería, Pedro Utrera Cortejosa, Rafael Ory Cristelly , Gabriel Mourente, Manuel Marchena, Luis Gorostiza, Ricardo Vallespín Gómez, Juan Pardo de Donlebun, Enrique Ferragut, Carlos Calvo, José Andrés Lobato, José Ramón Va- 
llespín, Domingo Galán, Guillermo Parrilla, , Mercedes Vallespín Gómez, Eliseo González Mosquera, Carlos Santiago Martín, Antonio Barbadillo, Pedro Valdecantos, Miguel López Nuche, Cesar Lazaga, Concha Vallespín, María Vallespín, Inés F. Vallespín y Mercedes F. Vallespín.

\section{Bibliografía}

ALMAGRO-GORBEA, Martín. 2008: La arqueología submarina hoy en España. Acceso el 14 de septiembre de 2020. www.histocast.com.

ALMAGRO-GORBEA, Martín. 2013: "La tumba de Melqart del Herákleion de Gadir". Madrider Mitteilungen, 54, pp. 159-202.

ALONSO VILLALOBOS, Carlos. 1991: Informe de la campaña de prospecciones subacuáticas en la zona noroeste de la playa de La Caleta. https:// www.juntadeandalucia.es/organismos/culturaypatarimoniohistorico/áreas/bines-culturales/actividades-arqueologicas/anua.

AMORES, Carmen. 1984: "En busca del mundo perdido". El País, Suplemento dominical, 24 de enero de 1984, pp. 19-22.

BASS, George F. 1973: "Dix-huit épaves méditerranéennes étudiées entre 1900 et 1968." L'archéologie subaquatique une discipline naissante. Unesco. Paris.

BENOIT, Fernand. 1961: "L'épave du Grand-Congloué". Galia, Suplemento 14. París.

BERNAL CASASOLA, Darío; SÁEZ ESPLIGARES, Antonio; SÁEZ ROMERO, Antonio Manuel; DÍAZ RODRÍGUEZ, José Juan; LORENZO MARTÍNEZ, Lorenzo; TOLEDO CUELLO, Francisco Javier. 2003: La Carta Arqueológica Municipal de San Fernando (Cádiz). Consejería de Cultura de la Junta de Andalucía. Sevilla.

BONSOR, Jorge Eduardo. 1918: "El terremoto de1504 en Carmona y en los Alcores (1918)". Boletín de la Real Sociedad Española de Historia Natural, tomo XVIII, pp. 115-126. Acceso el 10 de agosto de 2020. http://www.bibliotecavirtualdeandalucia.es/catalogo/catalogo imagenes/grupo.cmd?path=1005953.

BLANCO MINGUEZ, Concepción. 1970: "Nuevas piezas fenicias del Museo Arqueológico de Cádiz". Archivo Español de Arqueología, 43, pp. 50-61.

BLANCO FREIJEIRO, Antonio. 1985: "Los nuevos bronces de Sancti Petri". Boletín de la Real Academia de la Historia, 182, Cuaderno 2, pp. 207-216.
BLÁNQUEZ PÉREZ, Juan. 1982: "L’archéologie en Espagne". Histoire et archéologie. Dossiers, 65.

$\mathrm{BOSCH}$, Adolfo. Inédito: "Algunos aspectos la arqueología submarina de Cádiz".

BOUSCARAS, André. 1964: "Notes sur les recherches sous-marines d'Adge". Rivista di Studi Liguri, XXX, pp. 267-287.

BUSQUETS, Jordi. 1989: “La Expo abandonará la mayor operación arqueológica subacuática proyectada en España”. El País, 2 de noviembre de 1989.

CAMERON, James; JACOBOVICI, Simcha; DÍAZ-MONTEJANO, Georges. 2018: Rising Atlantis. 1973 Atlantis Expedition.

CEREZO ANDREO, Felipe. 2017: "Investigaciones arqueológicas de la UCA en el entorno de Sancti Petri. Resultados de la primera campaña en el pecio ARAPAL". Ponencia en Encuentros de Historia y Arqueología. www.uca.es/noticia/ estudiantes del máster de arqueologia nautica.

DAMIÁN, Max. 1986: Informe. Los dragados. ANDANA. Febrero.

DOMERGUE, Claude. 1966: "Les lingots de plomb romains du Musée archeologique de Cartagène et du Musée Naval de la Madrid". Archivo Español de Arqueología, vol. XXXIX.

E.M. 1993: "Bosch Lería recurre la resolución de Cultura sobre su colección incautada. La Audiencia Provincial estimó que no hubo delito". Diario de Cádiz, San Fernando. p. 13.

FERNÁNDEZ CANO, Víctor. 1973: Las defensas de Cádiz en la Edad Moderna. CSIC. Escuela de estudios hispano americanos. Sevilla.

GÁLVEZ, D. Rafael; LANDI, José. 1991: "Antonio Moreno conocía la existencia del tesoro arqueológico de Bosh Lería". El Periódico, San Fernando, 3 de octubre de 1991.

GALLARDO ABÁRZUZA, Mercedes; MARTÍ SOLANO, Josefa. 1994: Prospección arqueológica de emergencia en el caño de Sancti Petri. Acceso el $31 \mathrm{~d}$ agosto de 2020. https://www.juntadeandalucia.es/organismos/culturaypatarimoniohistorico/áreas/bines-culturales/actividades-arqueologicas/anua.

GALLARDO ABÁRZUZA, Mercedes; GARCÍA RIVERA, M. Carmen; VILLALOBOS, Alonso; MARTÍ, Josefa. 1995: Carta Arqueológica Subacuática de la Bahía de Cádiz. Acceso el 13 de agosto de 2020. www.sede.educación.gob.es/publiventa/cuadernos-de-arqueologia-maritima-n3-cartagena-1995/arqueologia/6839C-. 
GARCÍA Y BELLIDO, Antonio. 1945: España y los españoles hace dos mil años. Espasa Calpe. Buenos Aires.

GARCÍA Y BELLIDO, Antonio. 1964a: "Hercvles Gaditanvs". Archivo Español de Arqueología, 36, pp. 70-153.

GARCÍA Y BELLIDO, Antonio. 1964b: Hallazgos arqueológicos en Santipetri. Acceso el 28 de agosto de 2020. https://publicaciones.defensa.gob.es/revista-general-de-marina-167. $\underline{\mathrm{html}}$.

GAVALA Y LABORDE, Juan. 1959: La Geología de la Costa y Bahía de Cádiz y el poema "Ora Marítima" de Avieno. Madrid.

HIGUERAS-MILENA, Aurora. 1999: "Cautela arqueológica subacuática de urgencia al relleno de la zona de Puntales (Cádiz)". Anuario Arqueológico de Andalucía. Acceso el 5 de septiembre de 2020. https://www.juntadeandalucia.es/organismos/culturaypatarimoniohistorico/áreas/bines-culturales/actividades-arqueologicas/anua.

INGENIEROS CONSULTORES. 2010: Castillo de Sancti Petri, Cádiz. Acceso el 16 de septiembre de 2020. www.ines.es.

IVARS PERELLÓ, Juan. 1911: “El cuerpo de buzos de la Armada y la recuperación del Patrimonio Sumergido". La protección del Patrimonio Sumergido. Cuaderno monográfico, 62, pp. 41-57.

JIMÉNEZ VIALÁS, Helena. 2008: “Los paisajes que encontró Tarik. La bahía de Algeciras entre los siglos III y VIII." LVCENTVM, XXXVII, pp. 251269.

JUAN DE, Carlos; CIBECCHINI, Franca; MIRALLES, Juan. 2012: "El pecio Bou Ferrer (La Vila Joiosa-Alicante). Nuevos datos sobre su cargamento y primeras evidencias de la arquitectura naval". En F. NIETO y M. BETHENCOURT (coords.): Arqueología subacuática española: Actas del I Congreso de Arqueología Naútica y Subacuática Español, pp. 113-124. Servicio de Publicaciones de la Universidad de Cádiz. Cádiz.

LAMBOGLIA, Nino. 1952: "La nave romana di Albenga. Storia e vicende della scorperta". Rivista di Studi Liguri, 18, pp. 131-270.

LANDES INDUSTRIES CONTOIRS. 1980: Die Stadt und Bay von Cadiz mit ihrer Umgebung. Weimar. Acceso el 30 de septiemnbre de 2020. https://www.ing.es/web/catalogo-cartoteca/apibadasid/cartoteca/getAutthorityt650/15373.

M.C., Juman. 1973: “En aguas internacionales. Ha- llazgo de restos, que se cree pertenecen a una civilización Atlántida. Sucedió el lunes a unas 14 millas al Suroeste de Cádiz, a cargo de buceadores de la AMRA". Diario de Cádiz. Información local, 21 de julio de 1973, p. 8.

MARTÍNEZ MONTIEL, Fco. Javier; BARROS CANEDA, José R. 2000: Mas allá de las columnas de Hércules: cartas, planos y dibujos desde 1513 a 1823. Diputación de Cádiz. Cádiz.

MAS, Julio. 1972: Perspectivas actuales de la arqueología en Cartagena y su proyección submarina. Athenas Ediciones. Cartagena.

MOLINA, Luis. 1983: Una descripción anónima de Al-Andalus. Tomo II. Consejo Superior de Investigaciones Científicas. Instituto Miguel Asín. Madrid.

MORENO PÁRAMO, Agustín. 1970: “Corografía Gaditana de Pomponio Mela”. Cádiz Romana. Cádiz.

O’DONNELL, Hugo. 2013: "Razones históricas de España del caso Odyssey recuperado el 16 de noviembre del 2015". Acceso el 5 de septiembre de 2020. https://abcblogs.abc.es/ espejo-de-navegantes/pecios/razones-historicas-de-espana-del-caso-odyssey.html.

OLIVA PRAT, Miquel. 1958: "Estado actual de la Arqueología Submarina en la Costa Brava (Gerona, España). Últimas prospecciones y hallazgos. Avance para un estudio de conjunto." Atti del II ${ }^{\circ}$ Congresso Internazionale di archeologia Sottomarina, pp. 221-245. Instituto Internazionale di Studi Liguri. Albenga.

PALLARÉS SAVADOR, Francisca. 1972: “La primera exploración sistemática del pecio del Sec (Palma de Mallorca)". Forma Maris Antiqui Archéologie marine.

PARKER, Anthony J. 1992: Ancient Shipwrecks of the Mediterranean and the Roman Provinces, Tempvd Reparatvm. BAR Internacional, Series 580. Oxford.

PEMÁN Y PEMARTÍN, César. 1949: "Nuevas precisiones sobre vías romanas en la provincia de Cádiz". Archivo Español de Arqueología, 21, pp. 255-268.

PEMÁN Y PEMARTÍN, César. 1954: "Memoria sobre la situación arqueológica de la provincia de Cádiz en 1940". Informes y memorias, 1, pp. 11-55.

RICO, Christian; DOMERGUE, Claude. 2010: "Nuevos documentos sobre el comercio de los metales hispánicos en la época romana. Los lingotes de Chipiona" (Cádiz). Habis, 41, pp. 
163-184.

RIPOLL PERELLÓ, Eduardo. 1961: “La arqueología subacuática en España." Atti del II Congresso Internationale di Archeologia Sottomarina. Albenga 1958, pp. 246-250. Instituto Internazionale di Studi Liguri. Bordighera.

RODRÍGUEZ, Carlos; SANZ, Antonio; MARURI, Juan José. 2010: “Obras en el Castillo. ¿Destrozo de restos arqueológicos?". Acceso el 16 de septiembre de 2020. http://kdmsanctipetri. blogspot.com/2000/07/obras-en-el-castillo-2010.html.

RUÍZ AGUILAR, Susana; HIGUERAS-MILENA, José Manuel; MÁRQUEZ CARMONA, Lourdes. 2002: "Control y seguimiento de las obras del dragado del caño de Sancti Petri, Chiclana de la Frontera. Prospecciones subacuáticas previas y posteriores al dragado". Aceso el 5 de septiembre de 2020. https://www.juntadeandalucia.es/organismos/culturaypatarimoniohistorico/áreas/bines-culturales/actividades-arqueologicas/anua.

RUÍZ ALDEREGUÍA, Francisco. 2011: Cuaderno del románico de la Ribeira Sacra. Ediciones La Rectoral.

SÁEZ ESPLIGARES, Antonio. 2017: "La antigua Colección Municipal de Arqueología y el nuevo Museo Histórico Municipal de San Fernando". Boletín del Museo Arqueológico Nacional, 35, pp. 81-88.

SÁEZ ROMERO, Antonio; HIGERAS-MILENA, Aurora. 2018: "The Phoenicians and the Ocean: trade and worship at La Caleta, Spain". The International Journal of Nautical Archaeology, 47, pp. 81-102.

SÁNCHEZ-NAVARRO NEUMANN, Manuel. 1932: "Lista de terremotos más sentidos en la Península Ibérica". Acceso el 8 de agosto de 2020. http://www.ign.es/web/resources/sismologia/publicaciones//ListaTerremotosSanchezNavarro-1921.pdf.

SUAREZ DE SALAZAR, Juan Bautista. 1610: Grandezas y Antigüedades de la Isla y ciudad de Cadiz. Cádiz.

TYLECOTE, Ronald F. 1962: Metallurgy and Archaeology: a prehistory of metallurgy in the British Isles. Edward Arnold. Londres.

VALLEJO, Mariano. 1812 "Plano de la Bahía de Cádiz". Acceso el 30 de septiembre de 2020. https://www.ign.es/web/catalogo-cartoteca/ resources $/ \mathrm{html} / 016358 . \mathrm{html}$.
VALLESPÍN GÓMEZ, Olga. 1977: "Prospecciones submarinas en Cádiz, agosto 1973". Noticiario Arqueológico Hispánico, Arqueología, 5. pp. 289-293.

VALLESPÍN GÓMEZ, Olga. 1985: "Carta Arqueológica de La Caleta, Cádiz". VI Congreso de Arqueología Submarina de 1982, pp. 59-74. Ministerio de Educación Cultura y Deporte, Dirección General de Bellas Artes y de Conservación y Restauración de Bienes Culturales. Cartagena.

VALLESPÍN GÓMEZ, Olga. 1986a: "The Copper Wreck (Pecio del Cobre)". The International Journal of Nautical Archaeology an Underwater Exploration, 15.4, pp. 305-322.

VALLESPÍN GÓMEZ, Olga. 1986b: "Una contribución de la Armada al desarrollo de la arqueología submarina". Revista General de Marina, octubre, pp. 345-349.

VALLESPÍN GÓMEZ, Olga. 1986: "El Pecio del Cobre". II Encuentro de Historia y Arqueología. San Fernando. Delegación Municipal de Cultura.

VALLESPÍN GÓMEZ, Olga. 1995: “Cartografía de los pecios antiguos en el Mediterráneo-Aportaciones al conocimiento de las corrientes comerciales de al-Andalus". Casa de Velázquez. Barcos, navegación y comercio marítimo en al-Andalus. Seminario coordinado por Patrice Cressier.

VALLESPÍN GÓMEZ, Olga. 2000: "La Caleta: Puerto antiguo de Cádiz". En M. BARTHÈLEMY y M. E. AUBET (coords.): Actas del IV Congreso Internacional de Estudios Fenicios y Púnicos, volumen II, pp. 915-921. Servicio de Publicaciones de la Universidad de Cádiz. Cádiz.

VALLESPÍN GÓMEZ, Olga. Inédito: "Excavaciones arqueológicas submarinas en El Aculadero de La Caleta, Cádiz".

VV.AA. 1958: Atti del II ${ }^{o}$ Congreso Internazionale di Archaeologia Sottomarina e Arqueología Submarina. Instituto Internazionale di Studi Liguri. Albenga..

VV.AA. 1973: L'archaéologie subaquatique une discipline naissante. Unesco. Paris.

VV.AA. 1985: VI congreso Internacional de Arqueología Submarina. Cartagena 1982. Madrid.

VV.AA. 1988: La Arqueología Subacuática en España. Museo Nacional de Arqueología Marítima, Centro Nacional de Investigaciones Arqueológicas Submarinas. Ministerio de Cultura. Murcia. 